\title{
Structure of AGCM-Simulated Convectively Coupled Kelvin Waves and Sensitivity to Convective Parameterization
}

\author{
DARGAN M. W. FRIERSON \\ University of Washington, Seattle, Washington \\ DAEHYUN KIM* AND IN-SIK KANG \\ Seoul National University, Seoul, South Korea \\ MYONG-IN LEE \\ NASA GSFC, Greenbelt, Maryland \\ JIALIN LIN \\ The Ohio State University, Columbus, Ohio
}

(Manuscript received 19 October 2009, in final form 26 August 2010)

\begin{abstract}
A study of the convectively coupled Kelvin wave (CCKW) properties from a series of atmospheric general circulation model experiments over observed sea surface temperatures is presented. The simulations are performed with two different convection schemes (a mass flux scheme and a moisture convergence scheme) using a range of convective triggers, which inhibit convection in different ways. Increasing the strength of the convective trigger leads to significantly slower and more intense CCKW activity in both convection schemes. With the most stringent trigger in the mass flux scheme, the waves have realistic speed and variance and also exhibit clear shallow-to-deep-to-stratiform phase tilts in the vertical, as in observations. While adding a moisture trigger results in vertical phase tilts in the mass flux scheme, the moisture convergence scheme CCKWs show no such phase tilts even with a stringent convective trigger.

The changes in phase speed in the simulations are interpreted using the concept of "gross moist stability" (GMS). Inhibition of convection results in a more unstable tropical atmosphere in the time mean, and convection is shallower on average as well. Both of these effects lead to a smaller GMS, which leads to slower propagation of the waves, as expected from theoretical studies. Effects such as changes in radiative heating, atmospheric humidity, and vertical velocity following the wave have a relatively small effect on the GMS as compared with the time mean state determined by the convection scheme.
\end{abstract}

\section{Introduction}

It is well known that current general circulation models (GCMs) typically are plagued by a variety of difficulties in simulating the tropical atmosphere (Bretherton 2007). For instance, with respect to the mean climate, many models

\footnotetext{
* Current affiliation: Lamont-Doherty Earth Observatory, Columbia University, Palisades, New York.
}

Corresponding author address: Dargan M. W. Frierson, Department of Atmospheric Science, University of Washington, Box 351640, Seattle, WA 98195-1640.

E-mail: dargan@atmos.washington.edu suffer from a "double ITCZ" problem, in which the ITCZ exhibits two local maxima instead of one in the central and eastern Pacific (Mechoso et al. 1995; Lin 2007). When one examines the simulation of the variability within the tropics, the biases are even more severe. The most significant problems are a generally anemic strength of the variability and greatly increased phase speeds for the Madden-Julian oscillation (MJO) and the equatorial wave spectrum including Kelvin waves, equatorial Rossby (ER) waves, mixed Rossby-gravity (MRG) waves, eastward inertio-gravity (EIG) waves, and westward inertio-gravity (WIG) waves (Slingo et al. 1996; Lin et al. 2006; Straub et al. 2010).

The reasons for the deficiencies in simulating tropical variability remain somewhat obscure. For instance, even 
making classifications as broad as which convective closures simulate better variability is not always clear and has changed with time: whereas Slingo et al. (1996) found that GCMs with moisture convergence closures in their convection schemes performed worse, Lin et al. (2006) found that moisture convergence convection schemes produced the best variability. Because problems with tropical variability in GCMs are so widespread, the development of any parameterization that increases the intensity of tropical variability or decreases the phase speeds of the MJO and other convectively coupled equatorial waves (CCEWs) in a way that does not adversely affect the mean state of the tropics is a useful contribution. Additionally, any understanding of the reasons for these improvements can be useful for advancing GCM parameterizations in a more broad sense and for improving our understanding of tropical dynamics in general.

Illustration of small improvements in this direction has been given by Lin et al. (2008, hereafter LLKKF) where the authors add convective moisture triggers to the convection schemes and examine the effect on the MJO and other CCEWs. Such sensitivity of tropical variability to convective trigger has been previously shown in the modeling studies of Tokioka et al. (1988), Itoh (1989), Wang and Schlesinger (1999), Lee et al. (2003), and Zhang and $\mathrm{Mu}$ (2005). Additionally, the effect of moisture preconditioning on the MJO has been seen in observational studies by Maloney and Hartmann (1998), Kemball-Cook and Weare (2001), Sperber (2003), Seo and Kim (2003), Myers and Waliser (2003), Kiladis et al. (2005), and Tian et al. (2006). In LLKKF, we found that a more stringent trigger does indeed lead to increases in the strength of the variability and decreases in the phase speeds. A companion study to LLKKF, Lin et al. (2007), shows that the simulated waves are surprisingly insensitive to cloudradiative forcing (CRF), with little effect on phase speeds when CRF is varied over a wide range, although the wave variances are sensitive to the changes in CRF.

In this study we use the same simulations presented in the LLKKF study and focus more closely on the nonMJO CCEWs, recently reviewed by Kiladis et al. (2009). We put particular emphasis on the convectively coupled Kelvin waves (CCKWs) in the model, which are known to influence aspects of the tropical climate such as the Atlantic ITCZ (Wang and Fu 2007), variability over South America (Liebmann et al. 2009), precipitation over Africa (Mounier et al. 2007; Nguyen and Duvel 2008), Indian monsoon onset (Flatau et al. 2003), ENSO (Straub et al. 2006), and the MJO (Dunkerton and Crum 1995; Masunaga 2007; Roundy 2008). We examine in more detail the reasons for the changes in phase speed with convective trigger strength in the LLKKF study, as well as composites of typical structures of the CCKWs to compare with recent observations and composites presented in Wheeler and Kiladis (1999, hereafter WK), Wheeler et al. (2000), Straub and Kiladis (2002, 2003b), Roundy and Frank (2004), Yang et al. (2007a,b,c), and Kiladis et al. (2009).

A highlight of the recent observational work is the omnipresence of higher-mode baroclinic structure in the CCEWs (Kiladis et al. 2009; Mapes et al. 2006). It should be noted first that the baroclinic mode decomposition we use in this paper is convenient but not strictly valid: vertical propagation into the stratosphere is possible and is seen in the simulations presented here. While early theoretical work (e.g., Matsuno 1966; Gill 1980) simulated waves with first baroclinic mode structure, with velocity in the upper troposphere equal and opposite to the lower tropospheric velocity and vertical velocity with a single maximum in the midtroposphere, recent observations in the papers listed above suggest that second baroclinic mode structure is equally important in determining the structure of the waves (Wheeler et al. 2000; Straub and Kiladis 2003b; Haertel and Kiladis 2004; Kiladis et al. 2009). The second baroclinic mode structure exists in the waves as follows: there is convergence in the lower troposphere that leads the deep convection and slowly humidifies the free troposphere. The lower tropospheric convergence is typically associated with congestus clouds. Following the deep convection, there is a stratiform cloud deck trailing the convection center, with upward motion in the upper troposphere and downdrafts below this. This shallow-todeep-to-stratiform structure appears to occur self-similarly for nearly every type of tropical wave (Kiladis et al. 2009). Part of this paper will address to what extent the model is able to capture this observed vertical structure.

There are two primary theories of what determines the phase speed of CCEWs. A first theory is that the wave speed is determined by the "gross moist stability" (GMS) of the tropics (Neelin and Held 1987; Neelin et al. 1987; Neelin and Yu 1994; Frierson et al. 2004; Raymond et al. 2009). In this theory it is assumed that condensation reduces the effective static stability felt by rising parcels to a small positive value, a fact that is generally corroborated in observations (Yu et al. 1998; Back and Bretherton 2006). The waves propagate at a speed proportional to the square root of the GMS in this theory. Models that either prescribe GMS or parameterize the stability using empirically determined functions can create $\mathrm{CCEW}$ propagation speeds that are close to observations. GCM studies of a range of complexity that argue for the GMS setting phase speeds include Sobel and Bretherton (2003), Frierson (2007a), and LLKKF, which we expand upon in this study.

A key drawback to this theory is the presence of higher mode vertical structure in CCEWs. Since the observed waves are not solely first baroclinic in nature, as the theory above is developed for, it is unclear whether the GMS 
has any relevance for the CCEWs in the real atmosphere. An alternative theory that has been boosted by the recent vertical structure observations is that the second baroclinic mode structure present in the shallow convection and stratiform convection actually determines the speeds of the waves. The second mode wave propagation speed is slower than the first baroclinic mode phase speed for a dry gravity wave and resembles the observational values for CCEWs. Thus, if the entire wave structure is set by the shallow convection that leads, the wave may be expected to propagate at the second mode wave speed. This theory was pioneered by Mapes (2000) and has influenced simple modeling work by Majda and Shefter (2001), Khouider and Majda (2006a,b,c, 2007), and Kuang (2008).

In section 2, we describe the atmospheric GCM used in this study, including the different flavors of convective parameterizations and triggers used. In section 3 we examine the changes in phase speed and variance of the CCKWs for these simulations, as well as the geographical variance of CCKWs and its relation to mean precipitation. In section 4, we study the reasons for the changes in propagation speed of the waves and propose that changes in the GMS of the tropics are responsible for the changes in phase speed. We additionally consider composites of GMS and the role of cloud-radiative interactions in this section. In section 5, we study composites of vertical velocity, temperature, and humidity for the CCKWs to compare in particular with vertical structures found in observations. We then offer a summary and conclusions in section 7 .

\section{Model description}

The model used in this study is the Seoul National University atmospheric general circulation model (SNU AGCM). The model is a global spectral model, with 20 vertical levels in sigma coordinates and T42 horizontal resolution $\left(\sim 2.8^{\circ} \times 2.8^{\circ}\right)$. As mentioned above, these are a subset of the simulations studied in LLKKF.

Two different convection schemes are used in this study. The default convection scheme is a simplified ArakawaSchubert (SAS) mass flux scheme by Numaguti et al. (1995). Major simplifications and differences from Arakawa and Schubert (1974) and Moorthi and Suarez (1992) are described in detail in Numaguti et al. (1995) and Lee et al. (2003). Additionally used is the scheme of Kuo (1974), as well as a simulation with no convection scheme (i.e., largescale condensation only). The LLKKF study also used simulations with moist convective adjustment (Manabe et al. 1965), but we omit these simulations for brevity since their CCEW properties were all qualitatively similar to the simulation with large-scale condensation only. It should be noted that all of the convection schemes mentioned here act to adjust tropospheric temperatures toward profiles similar to a moist adiabat on a relatively short time scale, although the ease with this adjustment can occur depends strongly on the trigger strengths described later.

The large-scale condensation scheme (which is implemented for all convection schemes) consists of a prognostic microphysics parameterization for total cloud liquid water (Le Treut and Li 1991) with a diagnostic cloud fraction parameterization. A nonprecipitating shallow convection scheme (Tiedtke 1983) is also implemented in the model. The boundary layer scheme is a nonlocal diffusion scheme based on Holtslag and Boville (1993). The land surface model is from Bonan (1996). Radiative transfer is parameterized with a two-stream $k$-distribution scheme implemented by Nakajima et al. (1995). Other details of the model physics can be found in Lee et al. (2003).

Each of the convection schemes is additionally equipped with a convective trigger of variable strength. ${ }^{1}$ The SAS scheme uses a trigger based on Tokioka et al. (1988). With the Tokioka scheme, the entrainment rate of convective plumes $\mu$ is limited with the following equation:

$$
\mu_{\min }=\alpha / D \text {, }
$$

where $D$ is the depth of the planetary boundary layer and $\alpha$ is a nonnegative constant. Only convective plumes of $\mu \geq \mu_{\min }$ are triggered in the cumulus ensemble. We use values of $\alpha=0,0.05,0.1$, and 0.2 in this study, and we refer to larger values of $\alpha$ as "stronger" or "more stringent" convective triggers. A stronger trigger makes it more difficult for deep convection to occur. It is worth noting that the simulation with no convection scheme is the limit of $\alpha \rightarrow \infty$.

For the Kuo scheme, the total moisture convergence is divided into a fraction that is used to moisten the column and a fraction that is rained out. The fraction $b$ (allowed to range from 0 to 1 ) that is used for moistening is given by

$$
b=1-\frac{\mathrm{RH}-\mathrm{RH}_{a}}{\mathrm{RH}_{b}-\mathrm{RH}_{a}},
$$

where RH is the column-mean relative humidity (calculated as vertically integrated precipitable water over vertically integrated saturated precipitable water) and $\mathrm{RH}_{a}$ and $\mathrm{RH}_{b}$ are two tunable parameters. The standard values are $\mathrm{RH}_{a}=0.8$ and $\mathrm{RH}_{b}=0.9$, and we test the case of $\mathrm{RH}_{a}=0$ and $\mathrm{RH}_{b}=0.1$ for more frequently triggering convection (weaker trigger) and the case $\mathrm{RH}_{a}=0.9$ and $\mathrm{RH}_{b}=0.95$ to suppress convection (stronger trigger).

The weakest trigger Kuo simulation is an outlier as compared with the other simulations in many of the plots we present in this paper, and deserves further comment.

\footnotetext{
${ }^{1}$ While "convective trigger" often suggests an approach based on convective inhibition (CIN), our triggers are not based on CIN.
} 
TABLE 1. Description of the convection scheme and convective triggers for the sensitivity experiments.

\begin{tabular}{lll}
\hline \multicolumn{1}{c}{ Deep convection scheme } & \multicolumn{1}{c}{ Expt } & \multicolumn{1}{c}{ Convective trigger } \\
\hline Kuo & KUO1 & $\mathrm{RH}_{a}=0, \mathrm{RH}_{b}=0.1$ \\
& $\mathrm{KUO2}$ & $\mathrm{RH}_{a}=0.8, \mathrm{RH}_{b}=0.9$ \\
& $\mathrm{KUO3}$ & $\mathrm{RH}_{a}=0.9, \mathrm{RH}_{b}=0.95$ \\
Simplified Arakawa-Schubert & SAS0 & $\alpha=0$ \\
& SAS1 & $\alpha=0.05$ \\
& SAS2 & $\alpha=0.1$ \\
No deep convection & SAS3 & $\alpha=0.2$ \\
\hline
\end{tabular}

The critical relative humidity for precipitating convection in this case is 0 , and thus deep convection is triggered if there is moisture convergence, regardless of the humidity content. The critical relative humidities for the other two Kuo scheme cases, by contrast, are 0.8 and 0.9 . The weakest trigger Kuo scheme case thus provides an opposite extreme of the simulation with no convection scheme (which requires $100 \%$ relative humidity in a grid box for precipitation to occur).

Table 1 summarizes the simulations that are considered in this paper. Each run consists of 8-yr (1997-2004) simulations of the atmospheric model forced by observed seasonally varying sea surface temperatures (SSTs) and sea ice distributions provided by the Program for Climate Model Diagnosis and Intercomparison (PCMDI) as part of phase II of the Atmospheric Model Intercomparison Project (AMIP-II).

\section{CCKW properties}

We begin by summarizing the CCKW characteristics of the simulations by examining Wheeler-Kiladis diagrams (WK) for daily precipitation data. Since we are primarily focusing on the symmetric equatorial Kelvin waves, we first average the precipitation between $15^{\circ} \mathrm{N}$ and $15^{\circ} \mathrm{S}$, and perform space-time spectral analysis on this averaged time series. This procedure, as opposed to the standard WK procedure (which separates into symmetric and antisymmetric components, Fourier analyzes, and then averages), slightly emphasizes the Kelvin wave variability in comparison to other variances, but the estimated speeds and relative amplitudes are not affected (not shown). The space-time spectra are calculated for successive 128-day segments, with 78 days of overlap between each segment. We then smooth the fields repeatedly with a 1-2-1 filter in each direction to create a background spectrum and plot the raw spectra (smoothed once with a 1-2-1 filter for robustness) divided by the background. In Fig. 1, we plot the symmetric WK diagram for the eight simulations we study here. We focus on the dynamics of the Kelvin wave in this study primarily, as this wave is the most prominent mode of variability and is easily identified in any of the simulations. CCKW dispersion relations for equivalent depths of 12,25 , and $50 \mathrm{~m}$ are overlaid on the plots.

In Fig. 1, the SAS0 simulation has a large amount of variance in the Kelvin wave band, eastward propagation with a nondispersive character. However, this variance is at considerably higher speeds than observations: an average equivalent depth of approximately $55 \mathrm{~m}$ (corresponding to a phase speed of $23.2 \mathrm{~m} \mathrm{~s}^{-1}$ ) seems to be most appropriate for the SAS0 simulation, with significant variance ranging from 40 to $65 \mathrm{~m}$. As the convective trigger is strengthened for the SAS simulations, the Kelvin waves propagate with considerably slower speed. For the SAS1 simulation, the average equivalent depth is approximately $45 \mathrm{~m}\left(21 \mathrm{~m} \mathrm{~s}^{-1}\right)$, with significant variance ranging from 25 to $55 \mathrm{~m}$. The SAS2 simulation has average equivalent depth $35 \mathrm{~m}\left(18.5 \mathrm{~m} \mathrm{~s}^{-1}\right)$ and a range of 17-50 m, and the SAS3 simulation has an average equivalent depth of $30 \mathrm{~m}$ and range of $10-40 \mathrm{~m}$. The NOCO simulation, which as mentioned before is the limit of infinitely large Tokioka parameter in the SAS scheme, has average equivalent depth of $25 \mathrm{~m}\left(15.7 \mathrm{~m} \mathrm{~s}^{-1}\right)$ and a range of $10-50 \mathrm{~m}$. The NOCO simulation in particular shows a large range of equivalent depths. As described in LLKKF, the phase speed for the NOCO simulation is perhaps even too slow as compared to observations, in sharp contrast to the typical GCM simulation. The SAS simulations become progressively more realistic as the trigger is strengthened.

The simulations with the Kuo scheme show an extremely fast Kelvin wave for the KUO1 simulation, with average equivalent depth of approximately $90 \mathrm{~m}\left(29.7 \mathrm{~m} \mathrm{~s}^{-1}\right)$. The convective trigger causes a decrease in phase speed for the two Kuo simulations as well, but observed values are not attained for this scheme. The KUO2 and KUO3 simulations have average equivalent depths of around 55 and $50 \mathrm{~m}$, respectively, and ranges of 35-65 m. It is additionally notable that as compared to observations in WK, all the simulations have more power in the higher wavenumbers of the CCKWs relative to lower wavenumbers.

We next demonstrate the two-dimensional structure of the Kelvin wave variance in the simulations and compare with the mean precipitation in the simulations. In addition to quantifying the increase in CCKW variance with convective trigger in the simulations, establishing the variance structure for Kelvin wave precipitation allows us to make informed choices about averaging regions for GMS and vertical structure composites. We examine the mean precipitation distribution both to understand its effect on the CCKW variance structure and to examine the effect of convective triggers on precipitation biases. The filtering of the Kelvin wave band is accomplished by taking the Fourier transform in $x$ and $t$ for the entire time series 
a. SASO

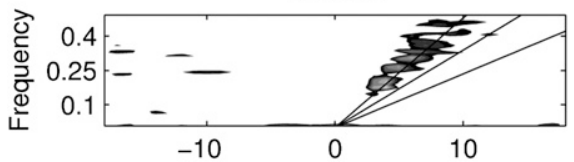

c. SAS2

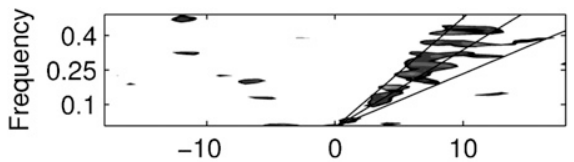

e. NOCO

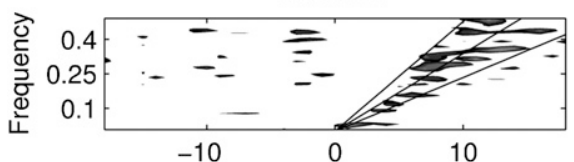

g. KUO2

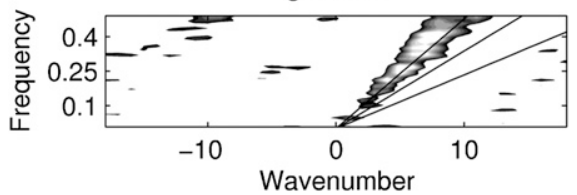

b. SAS1
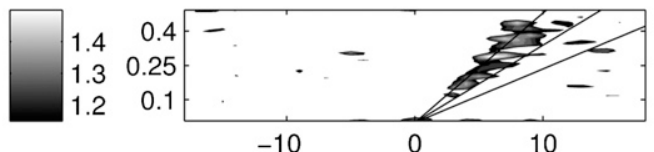

d. SAS3
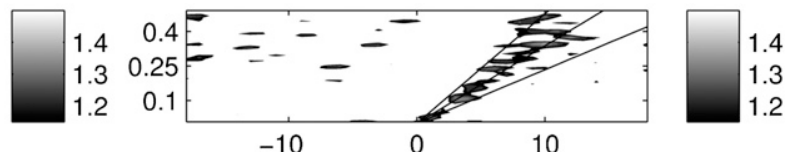

f. KUO1
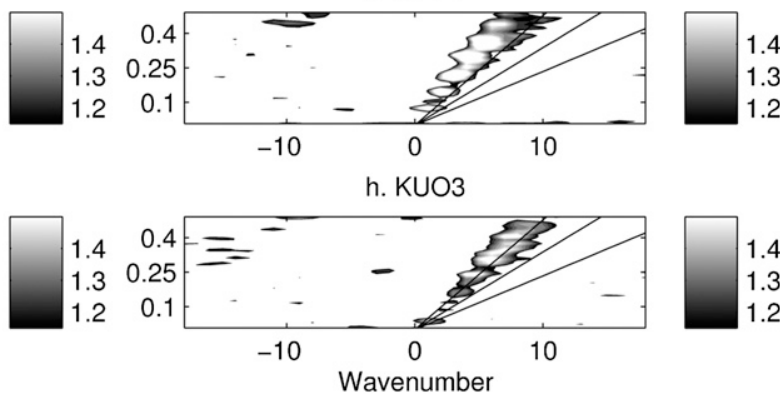

FIG. 1. Filtered wavenumber-frequency spectra for the symmetric component of precipitation, calculated following WK. Dispersion relations for the Kelvin wave with equivalent depths of 12,25 , and $50 \mathrm{~m}$ are additionally plotted.

and then zeroing out the westward-propagating signal and eastward-propagating signals with any of the following properties: frequency below $1 / 30 \mathrm{day}^{-1}$ or above $1 / 2.5$ day $^{-1}$, wavenumber below 1 or above 14 , and Kelvin wave equivalent depth above $90 \mathrm{~m}$ or below $8 \mathrm{~m}$. This set of properties is used to define the CCKW throughout this manuscript. Then, inverse transforms are used to reconstruct the Kelvin-filtered fields.

In Fig. 2, the daily standard deviation of the Kelvinfiltered precipitation is plotted for the four SAS simulations. As the trigger becomes more stringent, the CCKW intensity experiences a clear increase. Integrated across the tropics and between $10^{\circ} \mathrm{S}$ and $10^{\circ} \mathrm{N}$, there is a $19 \%$ increase in standard deviation between the SASO and SAS1 simulation, a 33\% increase in standard deviation between the SAS0 and SAS2 simulation, and a $60 \%$ increase in standard deviation between the SASO and SAS3 simulation. This increase is experienced essentially uniformly across the tropics. In the equatorial band, the regions of greatest variance include the Indian Ocean and the western Pacific, with an additional local maximum over the eastern Pacific/Amazon ITCZ. The Indian Ocean variance is centered along the equator in all cases and is primarily confined within $5^{\circ}$ of the equator. The western Pacific variance is more meridionally spread out and is confined more into ITCZ-like structures. In the South Pacific convergence zone (SPCZ) especially, the region of high standard deviation connects continuously with higher standard deviation regions in higher latitudes, possibly indicating some interaction with extratropical waves as in Straub and Kiladis (2003a).

In Fig. 3, this can be compared with the two-dimensional annual mean precipitation structure for the SAS simulations. Two clear inferences can be made from this plot: first, the increase in standard deviation in Fig. 2 is not due to increases in the mean precipitation, which stays similar from simulation to simulation. Second, the lack of sensitivity in the structure of the Kelvin wave variance occurs despite clear changes in the mean precipitation structure. For instance, there is a clear shift in precipitation from the northwestern Pacific ITCZ to the southwestern Pacific ITCZ as the trigger is made more stringent. This is not reflected in the Kelvin wave variance.

Comparing the structures of CCKW activity in Fig. 2 with observations as plotted in studies such as Roundy and Frank (2004), Kiladis et al. (2009), and Tulich et al. (2010) shows some level of agreement. For instance, the variance is largely symmetric about the equator in the Indian Ocean and shifts off-equator in the western Pacific, into the SPCZ and the central and eastern Pacific ITCZ. Systematic biases in the Kelvin wave variance include too strong variance in the model over Southeast Asia and the Philippines, and too small variance in the central Pacific ITCZ. These areas are also anomalous in the mean precipitation as seen in Fig. 3: the model simulations show too little precipitation in the central Pacific ITCZ and 


\section{a. CCKW Precipitation Std Dev (mm/day), SASO}

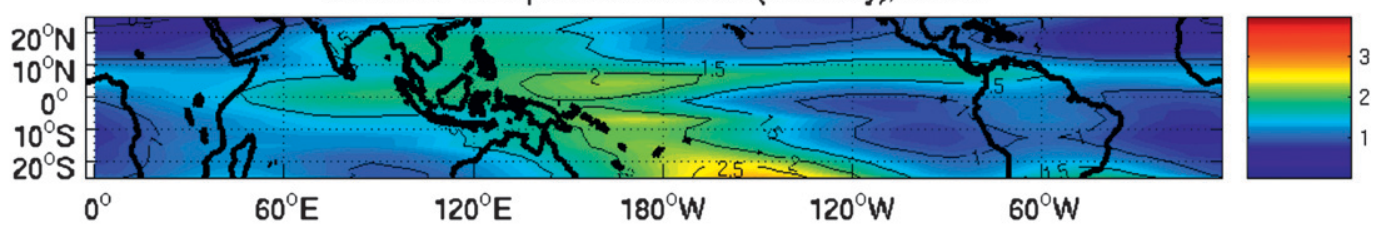

b. CCKW Precipitation Std Dev (mm/day), SAS1

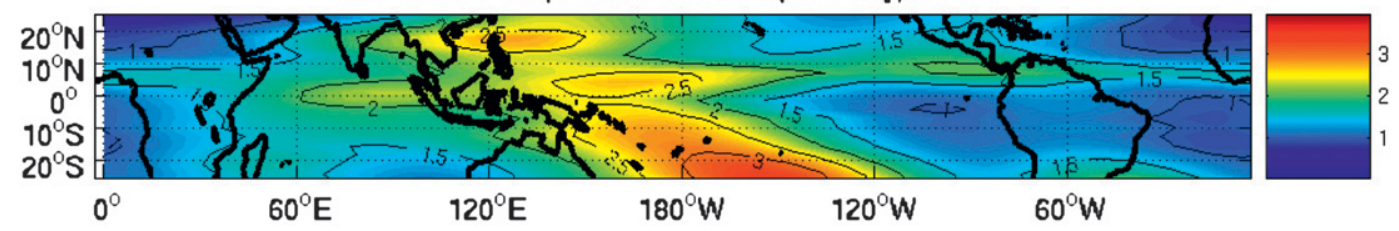

c. CCKW Precipitation Std Dev (mm/day), SAS2

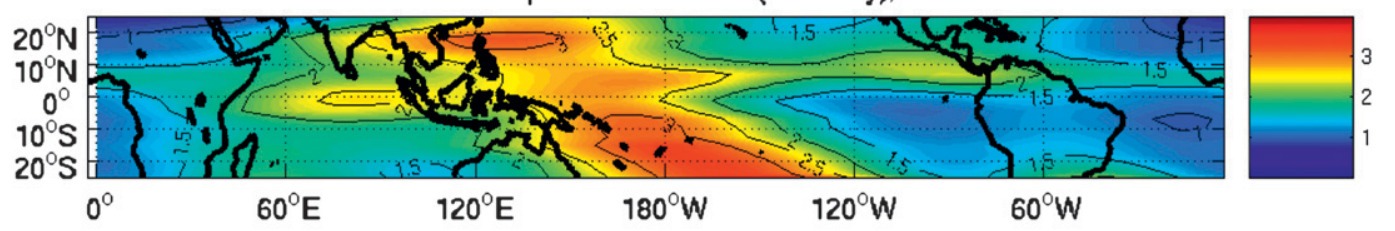

d. CCKW Precipitation Std Dev (mm/day), SAS3

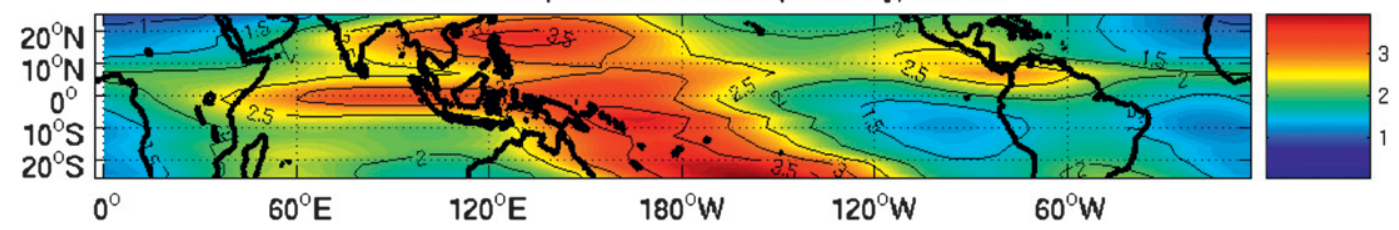

FIG. 2. Standard deviation of Kelvin-filtered precipitation $\left(\mathrm{mm} \mathrm{day}^{-1}\right)$ for the SAS simulations.

have anomalous maxima near the Philippines, with the latter feature seen especially in the stronger trigger cases. The off-equatorial bias of precipitation is common in high-resolution and cloud-resolving models (e.g., Tulich et al. 2010).

In Fig. 4, the standard deviation of the Kelvin-filtered precipitation is plotted for the NOCO and the KUO simulations (note the difference in scale between this figure and Fig. 2). The NOCO simulation has the largest standard deviation averaged between $10^{\circ} \mathrm{N}$ and $10^{\circ} \mathrm{S}$ of any of the simulations, $128 \%$ higher than the SAS0 simulation (this is additionally $42 \%$ higher than even the SAS3 simulation). The KUO1 simulation has significantly higher standard deviation ( $31 \%$ greater) than the SAS0 simulation before convective triggers are added, and these simulations additionally have a large increase in standard deviation as the convective trigger is strengthened. The KUO2 simulation has $30 \%$ increased standard deviation as compared with the KUO1 simulation, and the KUO3 simulation has $53 \%$ increased standard deviation as compared with the KUO1 simulation. The NOCO simulation has only slightly more standard deviation than the KUO3 simulation between $10^{\circ} \mathrm{N}$ and $10^{\circ} \mathrm{S}(14 \%)$, and the
KUO3 simulation has more variance when subtropical latitudes are considered.

The variance structures in the NOCO simulation are similar to the SAS simulations. There are additional shifts westward of the variance pattern at $\sim 15^{\circ} \mathrm{N}$ across Southeast Asia into the Bay of Bengal, but otherwise the structure is similar to the strong trigger SAS cases. In the KUO simulations, on the other hand, the variance structure changes significantly from case to case, in a manner that roughly reflects the changes of the structure of the mean precipitation in Fig. 5. For instance, the variance is largely confined in long and narrow ITCZs in the KUO1 case but is less meridionally confined in the $\mathrm{KUO} 2$ and $\mathrm{KUO} 3$ cases. The KUO1 simulation has a double ITCZ in mean precipitation, which is rather zonally symmetric across all basins, indicating a weak Walker circulation. The KUO2 and KUO3 simulations exhibit more asymmetry between the western and eastern Pacific. We also note that the averaging regions we choose in the western Pacific $\left(10^{\circ} \mathrm{N}-\right.$ $\left.10^{\circ} \mathrm{S}, 149^{\circ} \mathrm{E}-172^{\circ} \mathrm{W}\right)$ and Indian $\left(5^{\circ} \mathrm{N}-5^{\circ} \mathrm{S}, 65^{\circ}-93^{\circ} \mathrm{E}\right)$ basins in the next section are appropriate for all the SAS cases and the NOCO case, but they may not reflect the full structure in the KUO cases. 
a. Precipitation (mm/day), SASO

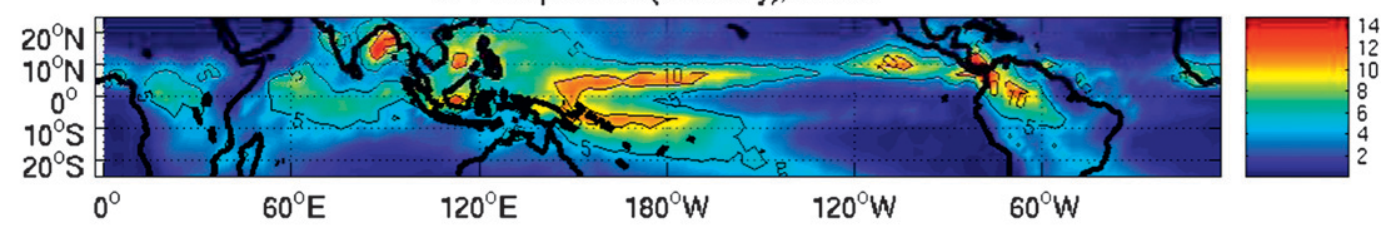

b. Precipitation (mm/day), SAS1

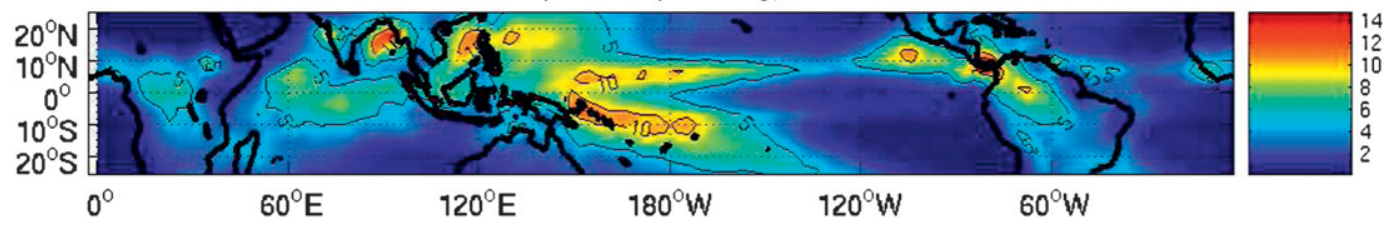

c. Precipitation (mm/day), SAS2

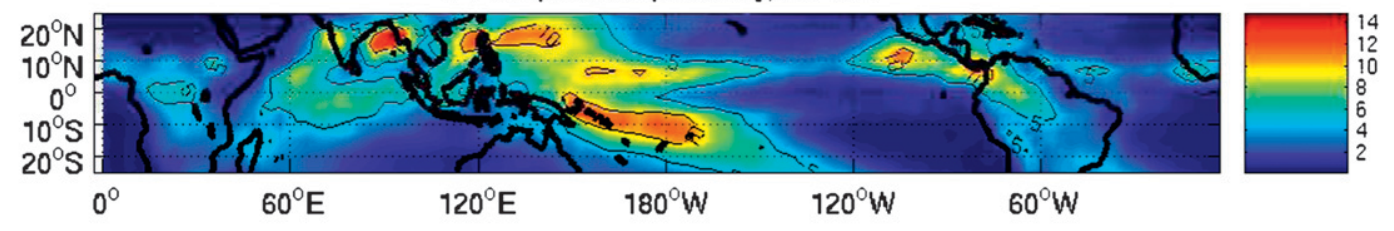

d. Precipitation (mm/day), SAS3

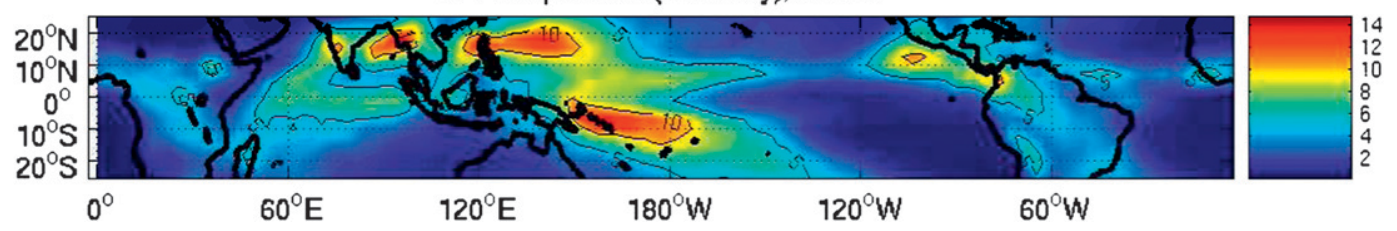

FIG. 3. Time-mean precipitation $\left(\mathrm{mm} \mathrm{day}^{-1}\right)$ for the SAS simulations.

Compared with observations, the NOCO simulation suffers the same problems as the SAS simulations in terms of its CCKW activity structure: excessive variance over Southeast Asia and a lack of variance over the central Pacific. These are again likely explained by the mean precipitation biases. The KUO simulations present a different set of biases in its variance structure, with KUO1 and the other two KUO simulations falling into two distinct categories. The KUO1 simulation shows a relatively impressive agreement with observations in terms of variance structure, with equatorially symmetric variance over the Indian Ocean shifting into the Northern Hemisphere ITCZ in Pacific Ocean. The primary deviations with observations are a double ITCZ-like structure over the Pacific Ocean and underestimations of activity over the continents, both of which are also biases in the mean precipitation. As the convective trigger is added to the KUO simulations, the variance structure shifts farther off the equator in the Pacific. The Indian Ocean exhibits an unrealistic local minimum in variance in the equatorial Indian Ocean and excessively high variance over the Indian subcontinent, Southeast Asia, and the SPCZ.

Generally speaking, as the convective trigger strength is increased in either convection scheme, the mean precipitation shifts away from the equator in the western Pacific and into the SPCZ and the area over and to the east of the Philippines. While not as strong a feature as the increase in CCEW variance or decrease in phase speed with convective trigger, the shifts in mean precipitation are present for both the Kuo and the SAS convection schemes and warrant further investigation.

\section{Gross moist stability}

The results above indicate that we can change phase speeds of CCKWs by nearly a factor of 2 , and the CCKW standard deviation by over a factor of 2 , by changing convection scheme parameters or the convection schemes themselves. We next address how aspects of the convection scheme and convective trigger cause such reductions in phase speed.

In the study of Frierson (2007a), we examine the response to convectively coupled Kelvin waves simulated in the idealized moist GCM of Frierson et al. (2006) with a simplified Betts-Miller convection scheme (Betts 1986; Betts and Miller 1986; Frierson 2007b). The finding of that study is similar to that presented here: the CCKWs are decelerated significantly as the convective criterion 
a. CCKW Precipitation Std Dev (mm/day), NOCO

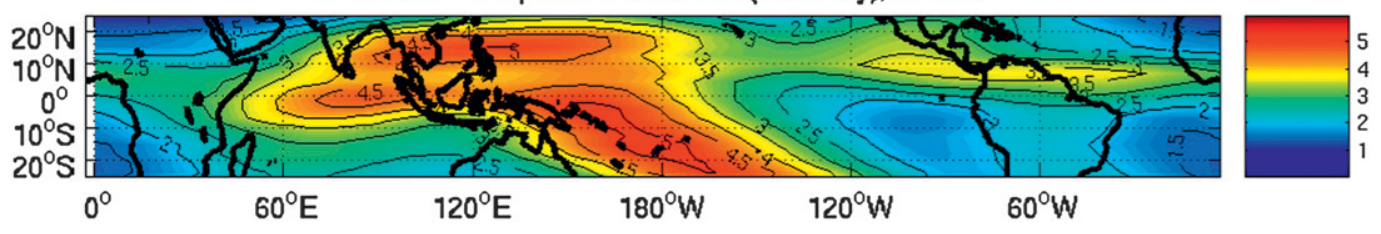

b. CCKW Precipitation Std Dev (mm/day), KUO1

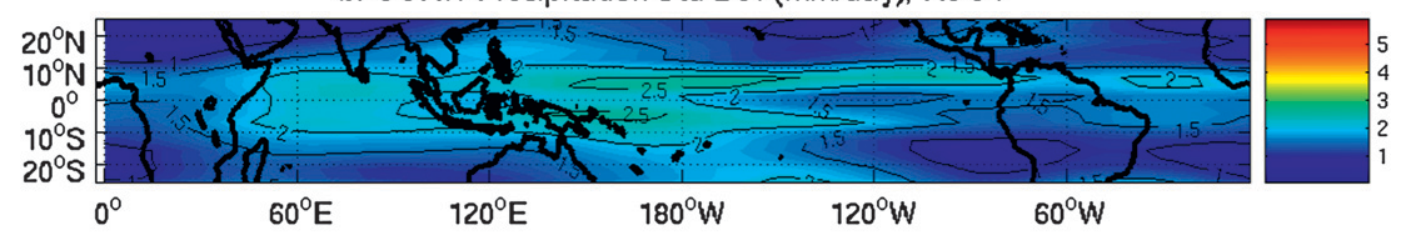

c. CCKW Precipitation Std Dev (mm/day), KUO2

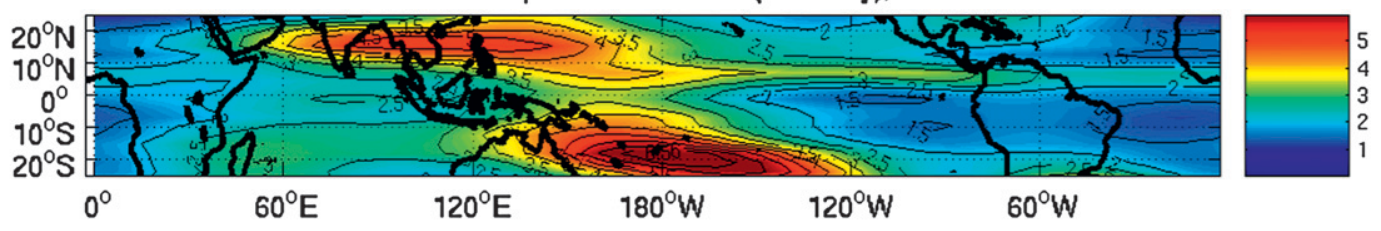

d. CCKW Precipitation Std Dev (mm/day), KUO3

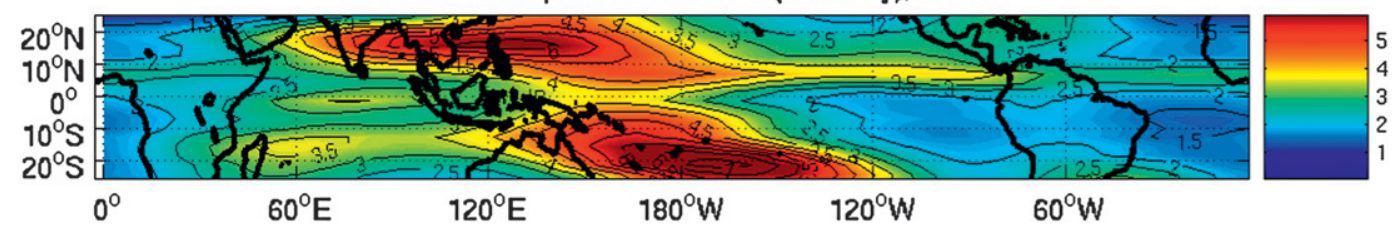

FIG. 4. Standard deviation of Kelvin-filtered precipitation $\left(\mathrm{mm} \mathrm{day}^{-1}\right.$ ) for the (a) NOCO and (b)-(d) KUO simulations. Note the difference in color scale from Fig. 2.

becomes more difficult to satisfy. This is similar to applying a convective trigger that prevents convection from occurring until the moisture content is sufficiently high. In the Frierson (2007a) study, the deceleration occurs because the GMS is decreased as the trigger is strengthened. With a higher convective trigger, the convection scheme is less efficient at convecting to higher levels and stabilizing the upper troposphere, leading to an atmosphere that is less stable in general and to slower wave speeds.

To study whether the same mechanism is present in these simulations, we first study the vertical structure of the moist static energy (MSE) in the simulations and compare with reanalysis data. In Fig. 6, we show the MSE (divided by $c_{p}$ to have units of Kelvin) averaged over a box in the western Pacific, between $149^{\circ} \mathrm{E}$ and $172^{\circ} \mathrm{W}$ longitude and $10^{\circ} \mathrm{N}$ and $10^{\circ} \mathrm{S}$ latitude. Figure 6a shows simulations with the SAS scheme, Fig. $6 \mathrm{~b}$ shows simulations with the NOCO scheme and the Kuo scheme, and in each panel we compare with European Centre for MediumRange Weather Forecasts (ECMWF) Re-Analysis (ERA)-Interim data (Uppala et al. 2008) from 1997 to 2004 to match the period of the simulation. These plots indicate that the lower tropospheric MSE is nearly identical for all simulations, with the exception of the KUO1 simulation. This is not surprising given the fixed SST lower boundary condition, which keeps all simulations pinned to nearly the same lower tropospheric temperature. The difference in the lower troposphere in the KUO1 simulation is due to a significantly lower tropospheric humidity content (there is approximately $25 \%$ less humidity in this simulation than in the other cases). The simulations show a positive bias compared with observations near the surface in all cases except KUO1 (which has a larger negative bias).

The upper tropospheric MSE, on the other hand, varies significantly from simulation to simulation. We note that since upper tropospheric moisture content is small, the differences in the upper troposphere are entirely due to dry static energy differences. The SAS simulations exhibit a systematic decrease of upper tropospheric MSE as the convective trigger is strengthened. An effect similar to that in the Frierson $(2007 \mathrm{a}, \mathrm{b})$ simulations is occurring: as the trigger becomes more stringent, the convection scheme is less effective at stabilizing higher levels of the atmosphere. The MSE at the 250-hPa level in the SAS3 simulation is $5 \mathrm{~K}$ colder than the SAS0 simulation. The 
a. Precipitation ( $\mathrm{mm} /$ day), NOCO

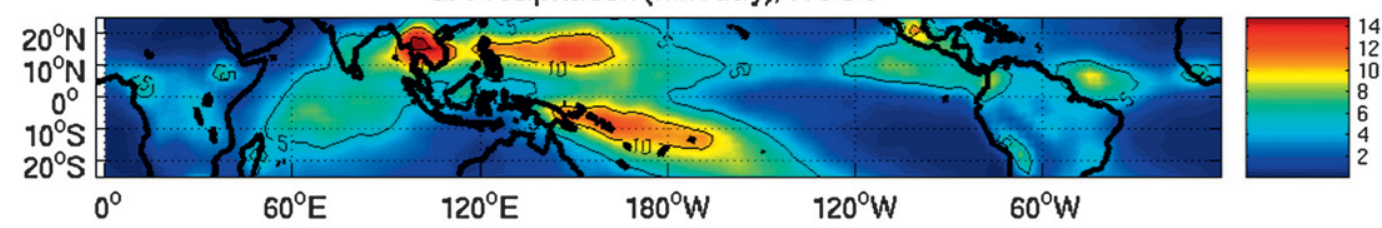

b. Precipitation (mm/day), KUO1

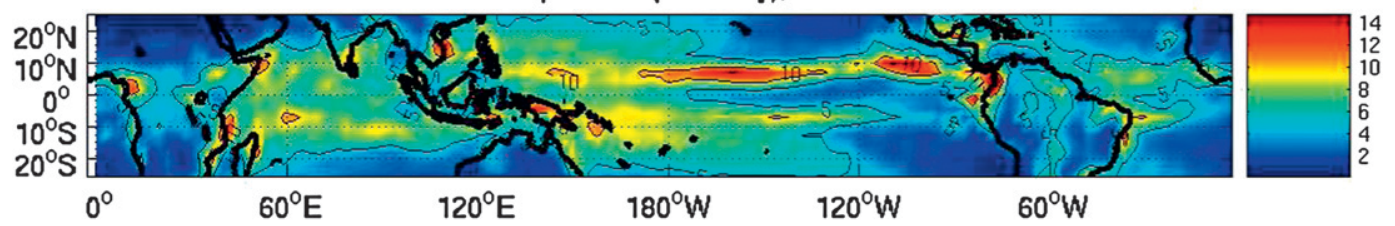

c. Precipitation (mm/day), KUO2

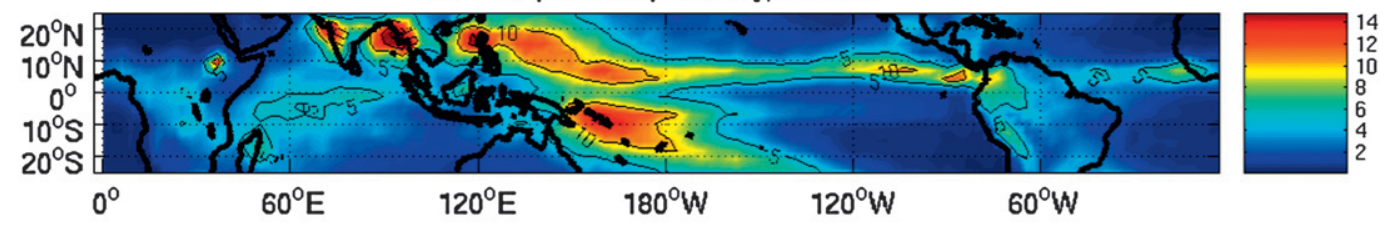

d. Precipitation (mm/day), KUO3

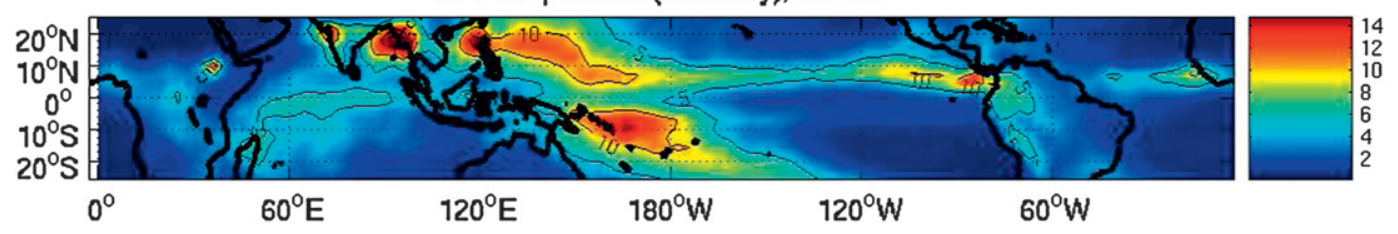

FIG. 5. Time-mean precipitation $\left(\mathrm{mm} \mathrm{day}^{-1}\right)$ for the (a) NOCO and (b)-(d) KUO simulations.

NOCO simulation has the coldest upper troposphere, by 1-2 $\mathrm{K}$ depending on the pressure level of comparison. The KUO1 simulation has a significantly different vertical structure of the MSE than any of the other cases, with significantly smaller MSE near the surface. There is also a pronounced minimum of MSE at $700 \mathrm{hPa}$ in the KUO1 case, although the upper tropospheric MSE is similar to the other cases. The KUO2 and KUO3 simulations are nearly identical to each other and are more similar to the SAS cases. The SAS cases compare favorably with the ERA-Interim data, with the SAS1 case perhaps showing the best agreement. The NOCO case shows a clear cold bias in the upper troposphere compared with the observations, while the KUO2 and $\mathrm{KUO} 3$ cases show a warm bias in the lower free troposphere and a cold bias near the tropopause.

Because temperature gradients are weak across the upper troposphere in the deep tropics, primarily because of the smallness of the Coriolis parameter at those latitudes (e.g., Sobel et al. 2001), the upper tropospheric MSE differences plotted for the western Pacific in Fig. 6 are representative of differences throughout the equatorial atmosphere (not shown). The lower tropospheric temperature and MSE vary with location across the deep tropics but are similar from case to case since these are primarily set by SST. Therefore at all locations the result remains that the MSE profile is less stable in the cases with stronger convective trigger.

The vertical profiles of divergence must also be calculated for each simulation to see how the GMS varies with the changes in the MSE profiles. We begin this investigation by revisiting the formula for the GMS $\Delta m$ for a vertically continuous atmosphere (Neelin and Held 1987; Frierson 2007a):

$$
\begin{aligned}
\nabla \cdot V_{2} & =\int_{p_{m}}^{p_{s}} \nabla \cdot \bar{V} \frac{d p}{g}, \\
\Delta m & =\int_{0}^{p_{s}} \bar{m} \boldsymbol{\nabla} \cdot \bar{V} \frac{d p}{g}\left(\boldsymbol{\nabla} \cdot V_{2}\right)^{-1},
\end{aligned}
$$

where overbars denote time means; $V$ is the horizontal velocity; $p$ is the pressure, with $p_{s}$ being the surface pressure and $p_{m}$ some midtropospheric pressure; and $m=c_{p} T+$ $g z+L q$ is the MSE, with $c_{p}$ being the specific heat of dry air at constant pressure, $T$ the temperature, $g$ the gravitational acceleration, $L$ the latent heat of vaporization of water, and $q$ the specific humidity. In this definition, 

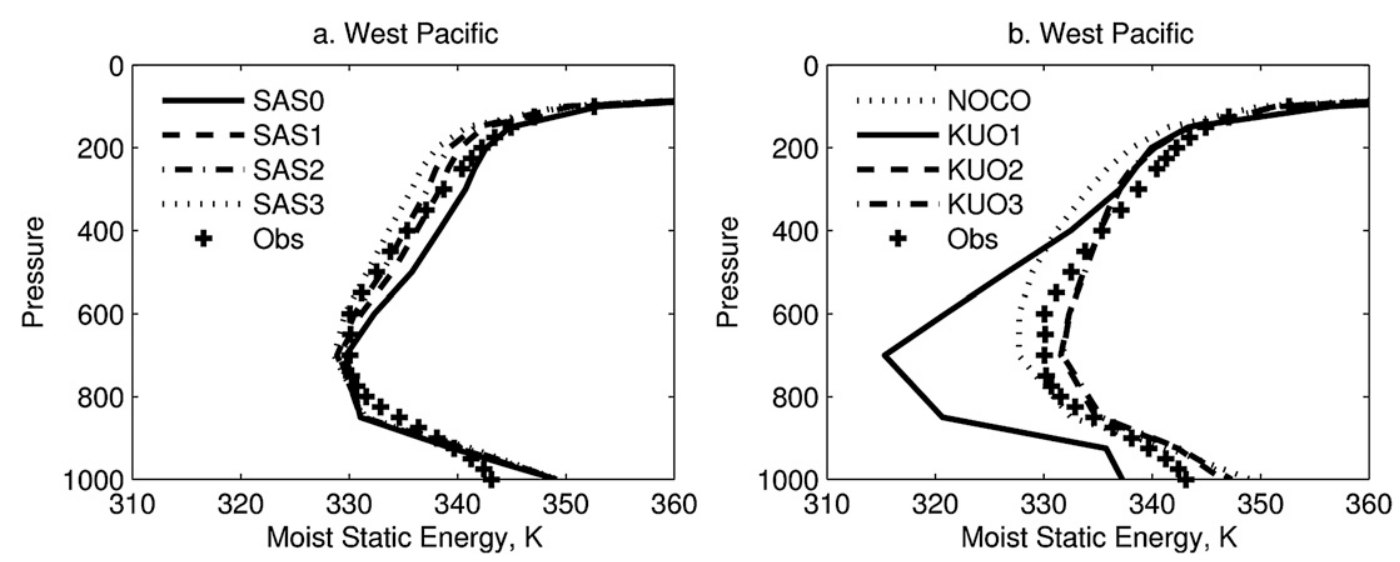

FIG. 6. Vertical profiles of MSE for simulations and ERA-Interim averaged over the western Pacific (between $10^{\circ} \mathrm{N}$ and $10^{\circ} \mathrm{S}$ latitude and $149^{\circ} \mathrm{E}$ and $172^{\circ} \mathrm{W}$ longitude).

$p_{m}$ is chosen so that the quantity $\nabla \cdot V_{2}$ is maximized for each column. The gross moist stability is a weighted average of the MSE profile, with the divergence profile acting as a weight. Assuming delta-function inflow and outflow for simplicity, the gross moist stability can be most simply interpreted as the average outflow MSE minus the average inflow MSE, and thus is a measure of vertical stratification. Clearly the vertical MSE profile is of great importance; however, changes in the typical convective depths (i.e., changes in the divergence profile) can have a strong influence as well. Therefore, we next examine changes in the divergence structure with convection scheme averaged over the two regions with the most convection and CCEW variance, the western Pacific and the Indian Ocean, plotted in Fig. 7. The western Pacific box is as before (between $10^{\circ} \mathrm{N}$ and $10^{\circ} \mathrm{S}$ latitude and $149^{\circ} \mathrm{E}$ and $172^{\circ} \mathrm{W}$ longitude, chosen as the maximum Kelvin wave variance in that region). The Indian Ocean box is chosen to capture the maximum variance in that basin, which is more equatorially confined than the western Pacific variance. We thus choose the box between $5^{\circ} \mathrm{N}$ and $5^{\circ} \mathrm{S}$ latitude and between $65^{\circ}$ and $93^{\circ} \mathrm{E}$ longitude.

For the SAS simulations in the western Pacific (Fig. 7a), the centroid of the upper tropospheric divergence occurs at slightly lower levels, on average, as the convective trigger is increased in strength. This is compensated by increased convergence in the lower to middle free troposphere. The boundary layer convergence is similar for all cases, likely because this is set by the SST gradients (Lindzen and Nigam 1987; Back and Bretherton 2009). The result on changes of the depth of convection can be identified even more readily in the Indian Ocean box (Fig. 7c): the upper tropospheric divergence extends to lower levels in the cases with stronger trigger. The Indian Ocean box exhibits stronger vertical motion in the cases with stronger convective trigger as well. The KUO1 simulation is again the most different from the other simulations, with significantly weaker and lower divergence than all other cases. As the trigger is strengthened for the KUO cases, the upper tropospheric divergence is increased, with the KUO2 and KUO3 simulations having similar vertical structure.

We examine the gross moist stability (again divided by $c_{p}$ to have units of Kelvin) for the western Pacific and Indian Ocean boxes in Fig. 8. The Indian Ocean figure is identical to that presented in LLKKF, while the western Pacific figure is slightly different because of a different averaging region. First baroclinic mode theory predicts that the equatorial wave speed be proportional to the square root of the gross moist stability. The gross moist stability can be directly compared to the equivalent depths estimated for the waves in section 3, as the wave speed is proportional to the square root of this quantity as well. The SAS simulations exhibit a uniform decrease of gross moist stability as the convective trigger is strengthened. In the western Pacific, this decrease is from $7.2 \mathrm{~K}$ in the SAS0 case to $4.1 \mathrm{~K}$ in the SAS3 case, while in the Indian Ocean the decrease is from $9.3 \mathrm{~K}$ in the SAS0 case to $4.5 \mathrm{~K}$ in the SAS3 case. We note that these decreases are roughly proportional to the decrease in equivalent depth for these simulations from 55 to $30 \mathrm{~m}$. The NOCO simulation has gross moist stability values of $4.2 \mathrm{~K}$ in the western Pacific and $3.4 \mathrm{~K}$ in the Indian Ocean. The KUO1 simulation has a significantly larger gross moist stability than any of the other simulations: $14.3 \mathrm{~K}$ in the western Pacific and $12.9 \mathrm{~K}$ in the Indian Ocean. The KUO2 and KUO3 simulations have gross moist stabilities that are reduced to similar values (between 5.1 and $5.7 \mathrm{~K}$ ) in both basins. The gross moist stabilities are roughly proportional to the estimated equivalent depths in all cases, with perhaps a slightly better fit in the Indian Ocean than the western Pacific.

One can use the simple theory of Tian and Ramanathan (2003) for a more quantitative comparison of the GMS 
a. West Pacific

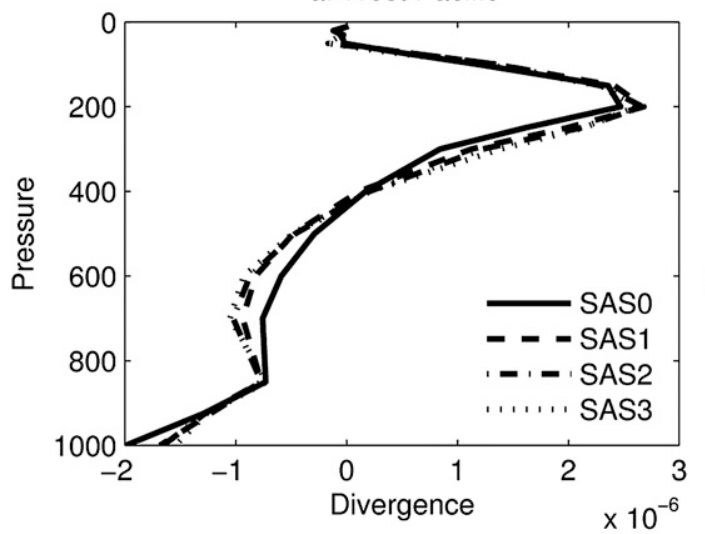

c. Indian

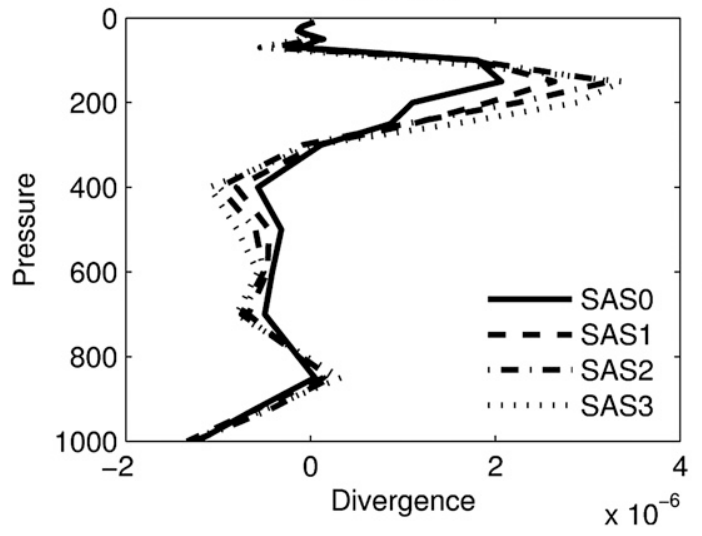

b. West Pacific

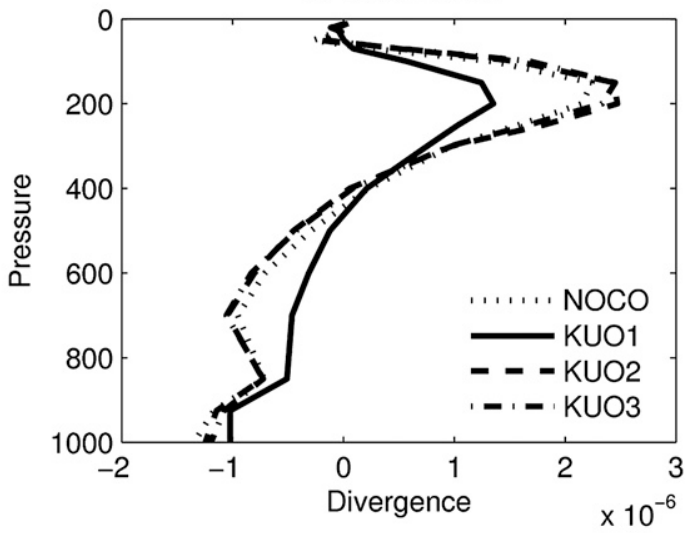

d. Indian

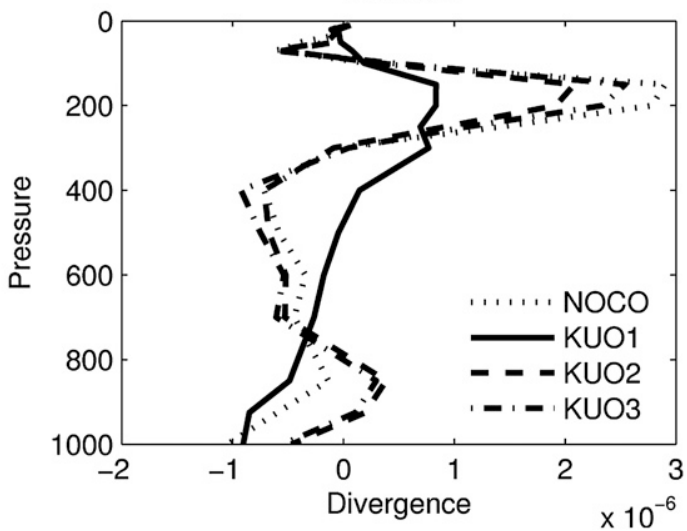

FIG. 7. Vertical profiles of the divergence averaged over (a),(b) the western Pacific (averaging region as in Fig. 6) and (c),(d) the Indian Ocean (between $5^{\circ} \mathrm{N}$ and $5^{\circ} \mathrm{S}$ latitude and $65^{\circ}$ and $93^{\circ} \mathrm{E}$ longitude).

with the equivalent depth estimates. Their formula for the equivalent depth as a function of GMS is

$$
h_{\mathrm{eq}}=\frac{R_{d} \Delta m \Delta p}{4 g c_{p} p_{m}},
$$

with $R_{d}$ is the gas constant for dry air, $\Delta p$ is the depth of the waves, and all other symbols are defined as before. We estimate $p_{m}$ and $\Delta p$ using the typical divergence profiles of the simulations in Fig. 7. We estimate $p_{m}=500 \mathrm{hPa}$ using the typical zero crossing of the divergence profile in the midtroposphere, and we use $\Delta p=450 \mathrm{hPa}$ using the typical spacing between the upper tropospheric divergence maximum $(200 \mathrm{hPa})$ and the lower-middle tropospheric divergence minimum $(650 \mathrm{hPa})$. This estimate is plotted as a straight line along with the equivalent depth estimates for each simulation and the GMS values for each basin in Fig. 9. The agreement is good, although we emphasize that significant variance is present over a range of phase speeds in Fig. 1, and the estimates of equivalent depths in Fig. 9 are rough estimates of the variance maxima for each simulation. The largest discrepancies are perhaps in the KUO2 and KUO3 simulations, which have larger equivalent depths than would be predicted from their gross moist stabilities. This is perhaps due to their different location of CCKW variance maxima, which is more off-equator in these simulations. The studies of Satoh (1994) and Frierson (2007b) show that GMS tends to increase away from the equator, but we do not attempt to further refine estimates of GMS for these simulations because of ambiguity with choice of averaging regions. In section 6 we provide additional estimates of the GMS by considering the stability felt by composited Kelvin wave events. We also examine the effect of radiative heating anomalies on creating an "effective GMS" in section 6.

\section{Vertical structure composites of the waves}

We next make composites of the vertical structure of the Kelvin waves using a linear least squares fit as in Wheeler et al. (2000) to examine whether any of the second-baroclinic mode structure seen in observations (Wheeler et al. 2000; Straub and Kiladis 2002, 2003b; Kiladis et al. 2009) is present in the simulated waves. We 

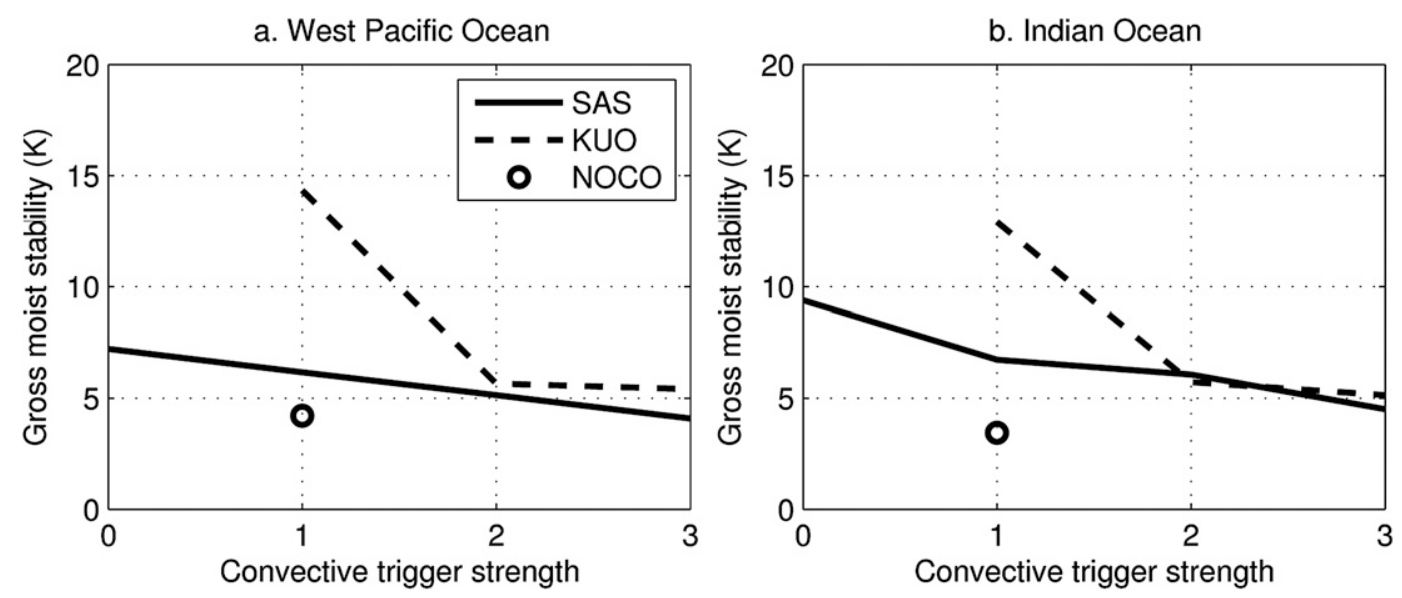

FIG. 8. Gross moist stability averaged over the (a) western Pacific and (b) Indian Ocean (averaging regions as in Fig. 7).

study the vertical structure of the Kelvin wave vertical velocity anomaly, humidity anomaly, and temperature anomaly around two base points, located at $160^{\circ} \mathrm{E}$ and the equator in the western Pacific and at $80^{\circ} \mathrm{E}$ and the equator in the Indian Ocean. The plots are centered about the base point and are scaled to twice the standard deviation of the Kelvin-filtered precipitation time series at the base to show amplitudes experienced in typical wave events, as in Wheeler et al. (2000).

We first plot the vertical structures of the pressure velocity anomaly in the western Pacific Ocean for the SAS simulations in Fig. 10. In all cases, the deep upward motion is centered around the base point at $160^{\circ} \mathrm{E}$ longitude, which occurs essentially by construction since the precipitation is composited about that location. In the SAS0 case, there is little indication of shallow convection leading the wave, as the vertical velocity contours are nearly vertical preceding the deep convection. There is, however, some indication of a phase tilt following the wave on the western side. In all of the other three SAS cases, there is a significant tilt of the vertical velocity throughout the wavelength, with shallow convection leading the wave, and high-level upward motion trailing in a stratiform region, as in observations. This plot suggests that as long as some convective trigger is used, there is low-level upward motion leading the wave. The simulation with no convective trigger has no such shallow convection leading.

To further investigate the structure of the SASO and SAS3 cases and their sensitivity to location, we plot the pressure velocity anomaly, the moisture perturbation, and the temperature perturbation of the waves around the Indian Ocean base point in Fig. 11. The pressure velocity composites exhibit the same characteristics as in the western Pacific basin, with little vertical tilt in the
SAS0 case and strong vertical tilt in the SAS3 case. There is even more significant vertical tilt in the Indian basin as compared to the western Pacific. Both simulations exhibit steady propagation of the moisture anomaly upward, with a positive moisture anomaly at low levels leading the deep convection. This feature is especially prominent in the SAS3 case, which also exhibits a positive moisture anomaly trailing in the midtroposphere.

Despite the lack of vertical velocity tilt in the SAS0 case, this simulation exhibits a warm-over-cold temperature anomaly over the deep convective region, as in observations. A similar structure with enhanced amplitude is seen in the SAS3 case, with warm-over-cold structure at the base point, a warm anomaly in the lower-middle troposphere leading the deep convection, and a cold anomaly in the upper-middle troposphere following the convection. There is additionally a strong signal in the stratosphere above the waves, indicating a vertical propagation of the Kelvin wave.

We plot the vertical structures for the pressure velocity around the western Pacific base point for the NOCO simulation and the KUO simulations in Fig. 12. The NOCO simulation exhibits a similar phase tilt as the SAS3 simulations, with slightly reduced stratiform convection tailing the base point. The KUO1 simulation exhibits essentially no tilt either preceding or trailing the wave. The KUO2 and KUO3 simulations exhibit essentially no tilt as well, with only a minor indication of some low-level convergence leading the deep convection. This indicates that the result about a convective trigger leading to enhanced shallow convection leading the wave is sensitive to the convection scheme that is used. The lack of shallow preconditioning in the KUO simulations may be due to the fact that the Kuo scheme is closed on vertically integrated moisture convergence and therefore is less 
a. West Pacific Ocean

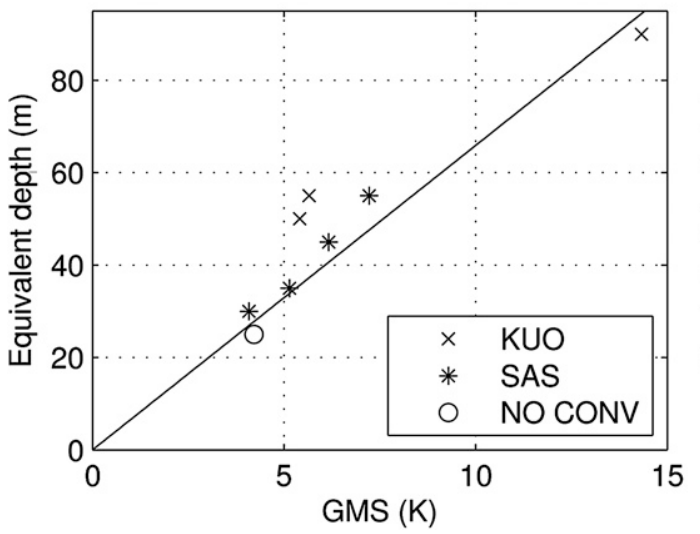

b. Indian Ocean

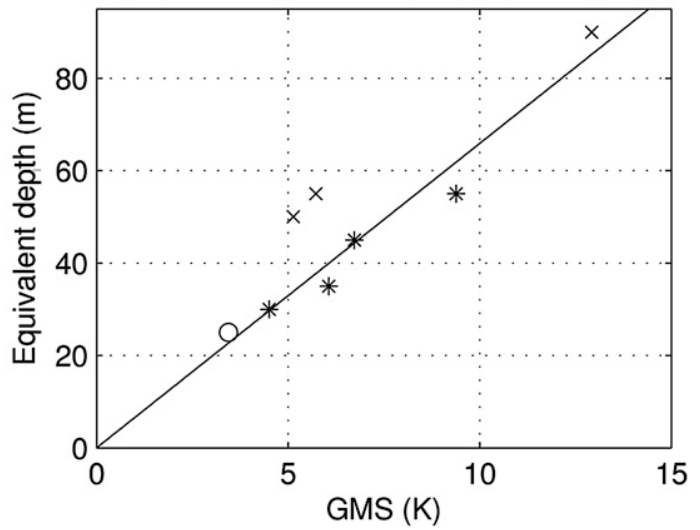

FIG. 9. Gross moist stability averaged over the (a) western Pacific and (b) Indian Ocean vs equivalent depth estimates.

sensitive to midtropospheric moisture than the entraining plume mass flux scheme.

A closer comparison of the KUO1 and KUO3 cases is presented for the Indian Ocean base point in Fig. 13. This basin additionally shows no vertical tilts for either KUO simulation. The moisture anomalies also show essentially no vertical tilt, although in the lower troposphere there is a small positive anomaly leading and a negative anomaly trailing in the KUO1 case, which is not seen in the KUO3 case. The temperature structures, on the other hand, show some interesting differences. The KUO1 case has none of the observed warm-over-cold anomaly over the deep convection. Instead, this case generally shows a warm anomaly leading the precipitation and a cold anomaly following, as predicted by first baroclinic mode theories. There is some higher-mode structure modulating this general feature as well. The KUO3 case, on the other hand, shows a well-defined warm-over-cold anomaly, despite the absence of second baroclinic mode structure in other fields. This temperature structure is seen in the western Pacific basin as well and is typical of the KUO2 simulation as well (not shown). Evidently the warm-overcold anomaly structure is easier for models to capture than the phase tilt of the vertical velocity, at least in this set of simulations. These results are an interesting contrast with the recent results of Straub et al. (2010), which shows that Kuo-type convection schemes are more likely to create realistic Kelvin wave variability, and they show realistic temperature and humidity profiles as well.

\section{Composites of the GMS and the effective GMS}

The gross moist stabilities calculated in section 4 are calculated using the time mean quantities but are not necessarily representative of the static stabilities that the waves feel at any given time. That is, in the previous section we have shown that the Kelvin waves exhibit systematic changes in their vertical velocity profiles in
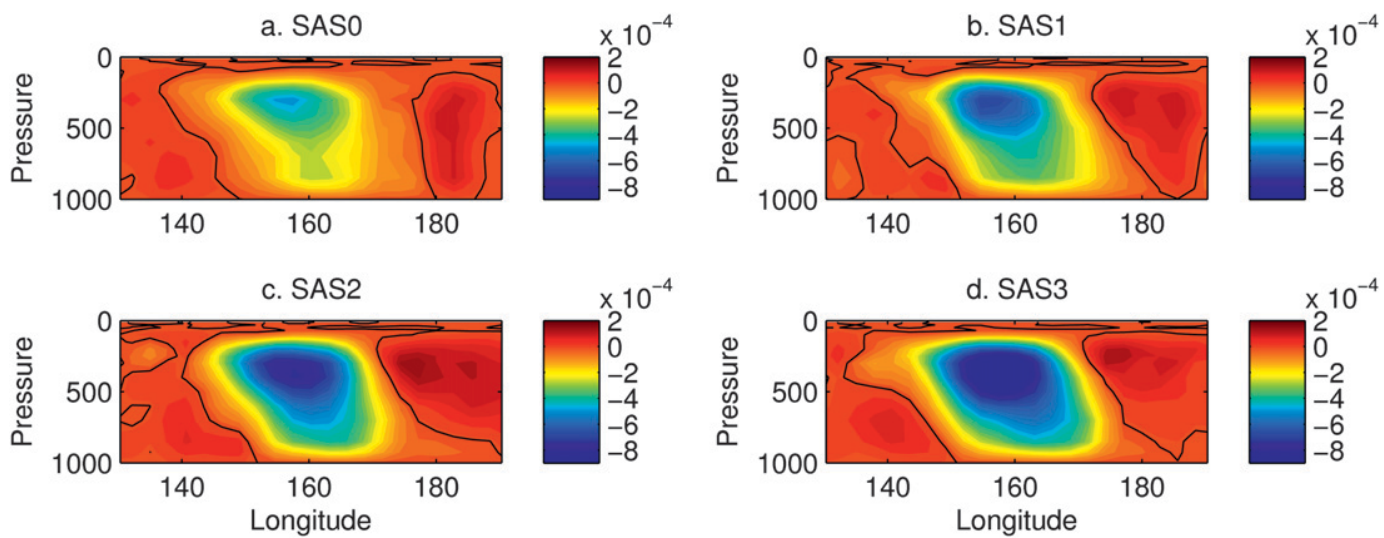

FIG. 10. Pressure velocity anomaly $\left(\mathrm{Pa} \mathrm{s}^{-1}\right)$ Kelvin wave composite for the SAS simulations around the base point of $160^{\circ} \mathrm{E}$ and the equator in the western Pacific. 

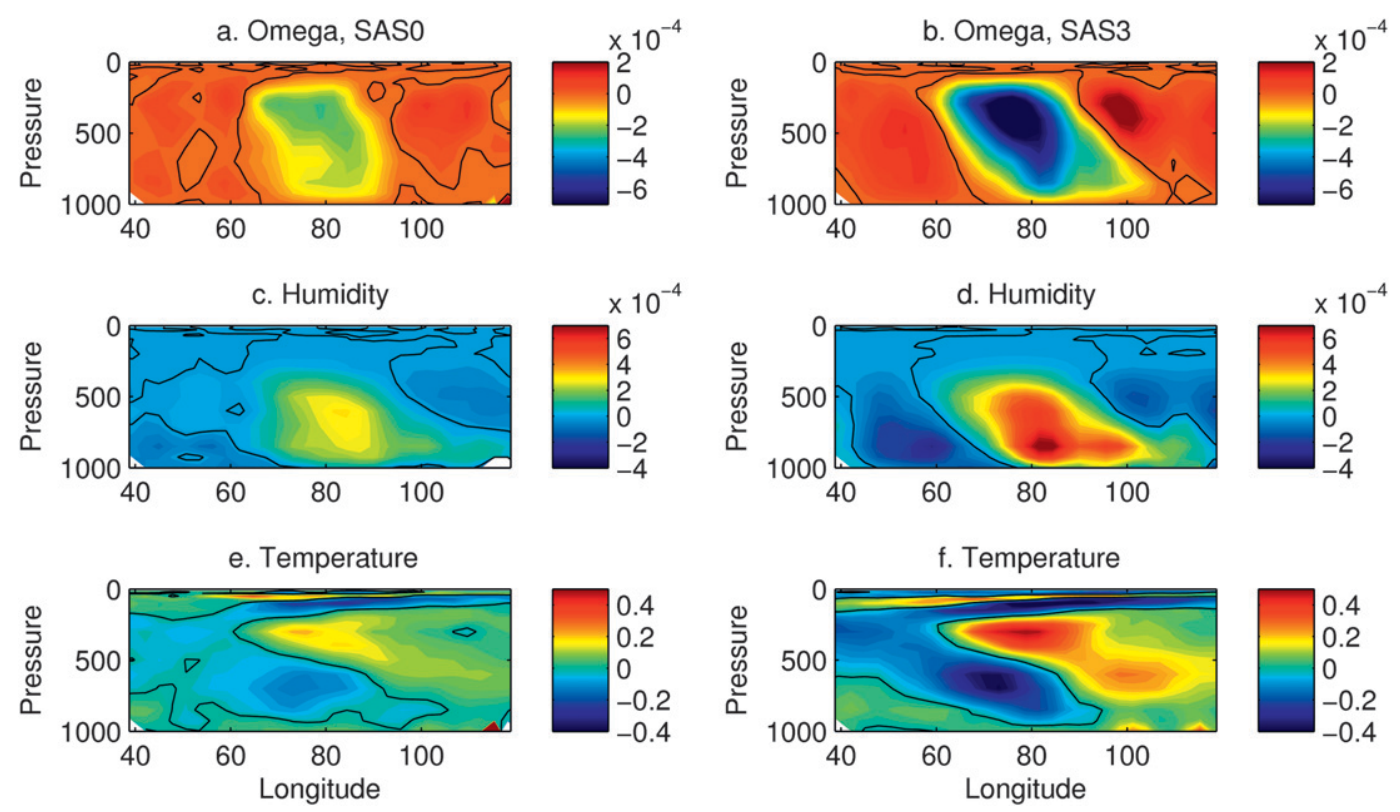

Fig. 11. (a),(b) Pressure velocity $\left(\mathrm{Pa} \mathrm{s}^{-1}\right),(\mathrm{c}),(\mathrm{d})$ specific humidity $\left(\mathrm{g} \mathrm{Kg}^{-1}\right)$, and (e),(f) temperature (K) anomaly Kelvin wave composites for the (left) SAS0 and (right) SAS3 simulations around the base point of $78^{\circ} \mathrm{E}$ and the equator in the Indian Ocean.

different phases of the waves, with shallow convection preceding deep convection preceding stratiform convection. Further, there are temperature and moisture anomalies associated with the wave passage as well. In this section we compare the GMS calculated using composites of the waves (i.e., using the mean fields plus wave composites corresponding to two standard deviations of Kelvin wave activity, as calculated in section 5) with the GMS calculated using time mean fields. We utilize Eqs. (3) and (4) in all these calculations, inputting either the mean or the composited MSE and divergence profiles, and we allow $p_{m}$ to vary when appropriate to maximize the integral of the divergence in Eq. (3).
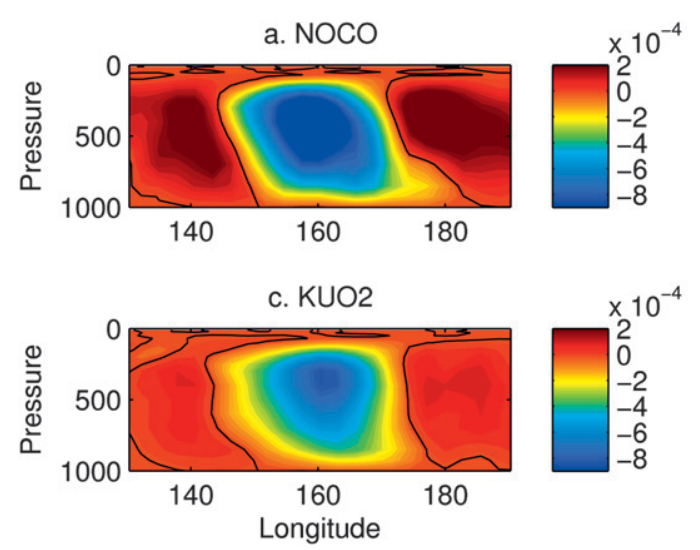

In Figs. 14a and 14b we plot the GMS difference between the composited state (using the western Pacific base point) and the mean state as a function of longitude at the equator. The changes in the GMS can thus be directly compared with the western Pacific pressure velocity anomaly composites in Figs. 10 and 12. Although the GMS differences in Figs. 14a and 14b are calculated using composited MSE and composited pressure velocity, the changes in the pressure velocity over the Kelvin wave phases explain nearly all the changes in the GMS. GMS differences calculated using the time mean MSE and the composited pressure velocity are nearly identical to those in Figs. 14a and 14b (not shown).
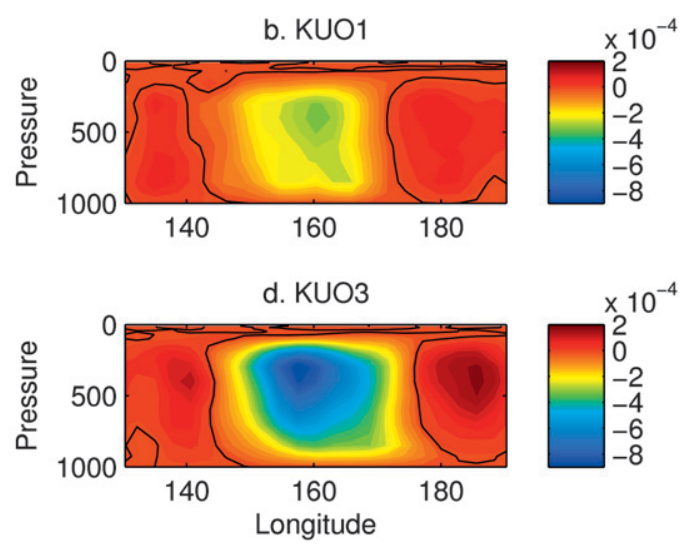

FIG. 12. Pressure velocity anomaly $\left(\mathrm{Pa} \mathrm{s}^{-1}\right.$ ) Kelvin wave composite for the (a) NOCO and (b)-(d) KUO simulations around the base point of $160^{\circ} \mathrm{E}$ and the equator in the western Pacific. 

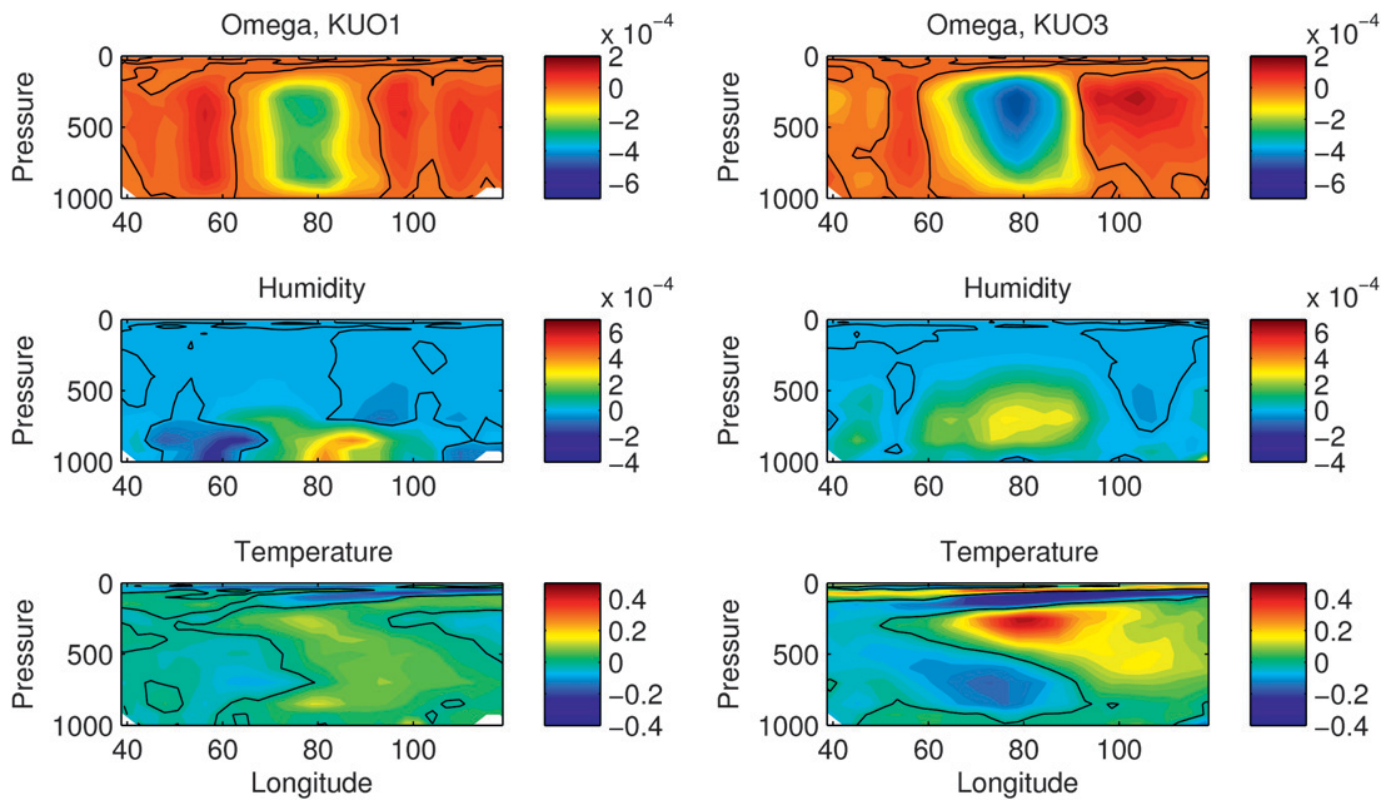

FIG. 13. (a),(b) Pressure velocity $\left(\mathrm{Pa} \mathrm{s}^{-1}\right)$, (c),(d) specific humidity $\left(\mathrm{g} \mathrm{Kg}^{-1}\right)$, and (e),(f) temperature (K) anomaly Kelvin wave composites for the (left) KUO1 and (right) KUO3 simulations around the base point of $78^{\circ} \mathrm{E}$ and the equator in the Indian Ocean.

For the KUO2, KUO3, and SAS0 cases, the Kelvin wave anomaly fields have essentially no effect on the GMS in Figs. 14a and 14b. This is due to the relatively small amplitude of the Kelvin wave signals and the fact that the pressure velocity anomaly retains a similar vertical structure throughout the passage of the waves. In the NOCO and SAS3 cases (and the SAS1 and SAS2 cases to a lesser extent), there are relatively strong systematic changes in the GMS. Specifically, the GMS is reduced to the east of the base point and increases to the west of the base point, with relatively little change at the base point itself. The reduction ahead of the base point is due to the enhanced presence of shallow convection in front of the wave, which converges high MSE air in the boundary layer and diverges the relatively low MSE air in the midtroposphere. Behind the base point, the vertical velocities are nearly opposite to that preceding the wave, with rising motion in the upper troposphere and sinking in the lower troposphere. This results in divergence occurring in the MSE-rich upper troposphere and boundary layer and convergence in the MSE-poor middle troposphere. The wave thus exports an additional amount of MSE per unit divergence to the west of the base point, resulting in a higher GMS. The KUO1 case exhibits a decrease in GMS due to compositing across the wave, resulting from small changes in the vertical profile of pressure velocity across the western Pacific.

With the exception of the KUO1 case, a notable feature of Figs. 14a and 14b is that the total change in GMS averaged across the western Pacific is relatively small for all cases. Further, at the base point, where the precipitation is maximum and where the GMS is likely most important for determining the phase speed, there is also almost no change in GMS for most of the cases. Exceptions to these conclusions are the NOCO case and the KUO1 case. Locally, the change in GMS due to compositing can be a similar size to the mean GMS calculated in Fig. 8 (e.g., in the SAS3 or NOCO cases). However, because of the small change in GMS due to compositing near the base point or averaged over the domain, we find little need to revise the theoretical relation shown in Fig. 9 based on this analysis.

Radiative heating terms can additionally play a role in determining the effective static stability felt by waves. Since deep clouds reduce the outgoing longwave radiation that can escape to space, the radiative heating within the atmosphere typically is highly correlated with precipitation. Several modeling studies have demonstrated how radiative heating can affect the amplitude and phase speed of intraseasonal oscillations or convectively coupled waves (Raymond 2001; Sobel et al. 2004; Bony and Emanuel 2005; Peters and Bretherton 2005; Bretherton et al. 2006). We examine the effect of cloud-radiative interactions on the effective static stability by additionally considering composites of the vertically integrated radiative tendencies. Since radiative cooling comes into the right-hand side of the moist static energy equation alongside terms such as $-m \boldsymbol{\nabla} \cdot V$, an effective gross moist 
a. GMS difference due to compositing

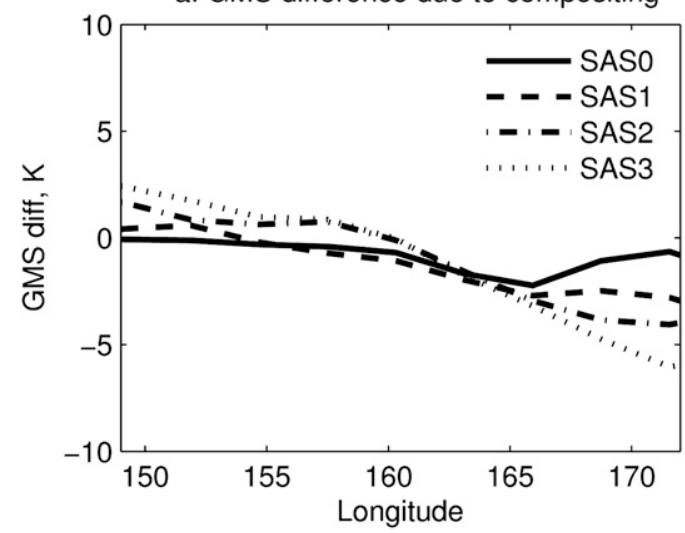

c. Effective GMS difference due to radiation

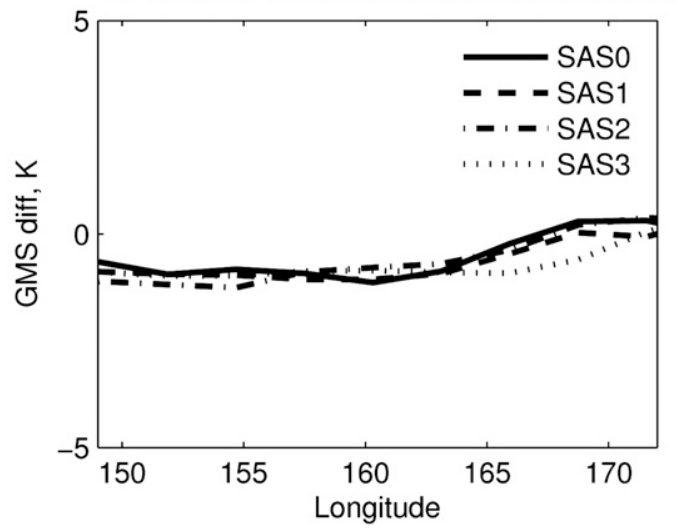

b. GMS difference due to compositing

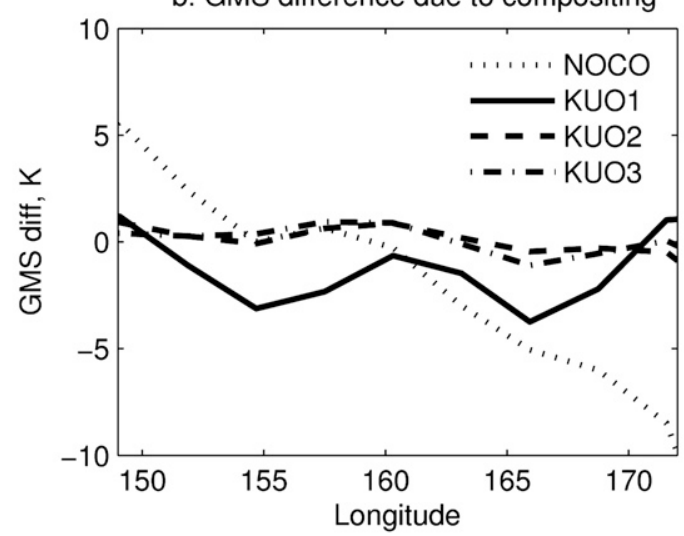

d. Effective GMS difference due to radiation

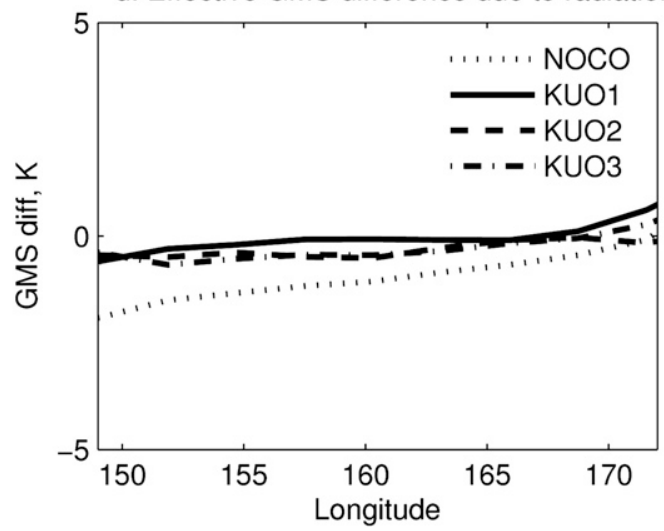

FIG. 14. Difference in gross moist stability or effective gross moist stability (K) over the western Pacific due to (a),(b) compositing based on two standard deviations of Kelvin wave variance and (c),(d) radiative heating anomalies.

stability, is constructed by dividing the vertical integral of the radiative cooling by the integral of the divergence through the midtroposphere; that is,

$$
\Delta m_{\mathrm{eff}}=\Delta m-\left(\nabla \cdot V_{2}\right)^{-1} \int_{0}^{p_{s}} Q_{r} \frac{d p}{g}
$$

where $Q_{r}$ is the radiative heating rate. This can be compared with the vertical integration and division by integrated divergence of the $m \boldsymbol{\nabla} \cdot V$ term in the GMS definition of Eq. (4). The change in effective GMS due to radiation-that is, the second term on the RHS of Eq. (6) - is plotted in Figs. 14c and 14d. The effective GMS reduction due to radiative cooling is relatively small in all the simulations, as the effective GMS is always reduced by less than $2 \mathrm{~K}$ everywhere. Systematic decreases do occur, especially in the area near and to the west of the base point, but these changes are less than $1 \mathrm{~K}$ on average for all cases except for the NOCO case. We conclude from these investigations of the role of anomalous vertical motion and anomalous radiative cooling that the mean
GMS values calculated in section 4 are adequate to explain the changes in phase speed of the waves.

\section{Conclusions}

By adding a convective trigger, we have shown that the speed of CCKWs (and more generally the full CCEW spectrum as shown in LLKKF) in this model can be decreased significantly to realistic values compared with observations. The variance in the CCKW band additionally increases greatly with a stronger trigger. The increase in variance occurs in a manner that is not simply reflective of local changes in mean precipitation, although some of the biases in the CCKW variance can be understood by considering the mean precipitation biases. As the convective trigger is strengthened, the mean precipitation shifts away from the equator in the western Pacific into the SPCZ and to the east of the Philippines, and this is reflected in the CCKW variance as well.

The CCKW phase speeds vary between $15.7 \mathrm{~m} \mathrm{~s}^{-1}$ (equivalent depth of $25 \mathrm{~m}$ ) for the simulation with no 
convection scheme and $29.7 \mathrm{~m} \mathrm{~s}^{-1}$ (equivalent depth of $90 \mathrm{~m}$ ) for the simulation with the Kuo convection scheme with the least stringent convective triggering (although precise measurement is difficult because Kelvin wave variance appears in a somewhat wide swath of phase speeds in all simulations). We interpret the changes in speed of the CCKWs with the concept of "gross moist stability" (Neelin and Held 1987). As the convective trigger is added and increased in strength, the convection scheme becomes less efficient at warming the upper troposphere. This decrease in upper tropospheric moist static energy combined with a decrease in the depth of convection leads to a decrease in the GMS. The decreases in GMS are shown to be correlated with the decreases in equivalent depth of the Kelvin wave.

This result suggests that the first baroclinic mode and its static stability controls the phase speed of CCEWs, a result that has been shown in previous modeling studies of Sobel and Bretherton (2003), Frierson (2007a), and LLKKF. However, in this study we also demonstrate that some of the waves additionally have second baroclinic mode structure, as in observations (Kiladis et al. 2009). The simulations with no convection scheme or the SAS scheme with any strength convective trigger show clear tilts from shallow to deep to stratiform convection. The simulations with the Kuo scheme show no such second baroclinic mode structure, similar to the simulations with the simplified Betts-Miller scheme in the idealized GCM simulations of Frierson (2007a).

Comparing the presence or absence of the second baroclinic mode structure with the estimated phase speeds from section 3 shows that there is no apparent connection between second baroclinic mode structure and the phase speed of the modes. On the other hand, the gross moist stability of the first baroclinic mode appears to be adequate to explain the phase speeds in all cases, whether second baroclinic mode structure exists or not. The second baroclinic mode structure may play a modulating role on the phase speeds, which are primarily set by the first baroclinic mode GMS. For instance, the KUO simulations, which have no second baroclinic structure, tend to have higher equivalent depths as compared with their GMS values in Fig. 9. A possible explanation is that the second baroclinic mode structure reduces the effective GMS in front of the wave in the SAS and NOCO cases, thereby creating slightly slower propagation speeds. We emphasize that the equivalent depths in Fig. 9 are all simply estimates from the Wheeler-Kiladis diagrams in Fig. 1. Each simulation shows a relatively wide range of phase speeds in the CCKW band in Fig. 1, so it is difficult to make conclusions about small phase speed modulations with certainty.

Several interesting open questions are posed by these simulations. First, the addition of the convective trigger leads to systematic changes in the mean precipitation as well as the variability. Work such as Frierson (2007b) and Kang et al. (2009) connects changes in mean precipitation to the GMS as well; it is an open question whether these ideas can be applied in the full GCM context here. The aquaplanet full GCM study of Kang et al. (2008) suggests that cloud feedbacks can also be important in determining the location of precipitation maxima. Further, the shifts in precipitation as the convective trigger is strengthened in these simulations appear to be away from locations with large SST gradients such as the central Pacific, over which boundary layer convergence would be an important mechanism in fueling convection (Lindzen and Nigam 1987; Back and Bretherton 2009). Theoretical work such as that of Sobel and Neelin (2006) may be useful in determining what determines the precipitation over these different areas.

A better understanding for the reasons that second baroclinic structure occurs in composites of CCEWs is needed. Relatively few studies have examined the structure of composites of CCEWs in comprehensive GCMs or cloud-resolving models (Peters and Bretherton 2005; Tulich et al. 2007; Tulich and Mapes 2008; Tulich et al. 2010; Straub et al. 2010). The work here suggests that moisture preconditioning is important in creating the second baroclinic mode structure, but the difference in response between the two convection schemes suggests that the properties of the convection are important as well. The simulations here show that second baroclinic structures are more readily seen in fields such as temperature and specific humidity than in vertical velocity. Observations show strong second baroclinic structure in all of these fields. In the recent study of Straub et al. (2010), GCMs with well-simulated CCKWs tend to have realistic second baroclinic mode structures as well; interestingly, of the five models which simulate realistic CCKWs, some utilize Kuo-type schemes whereas none use adjustment schemes.

A final question is whether the systematic changes seen as the convective trigger is strengthened can be seen in other GCMs, with diverse sets of parameterizations and different sets of triggers [including those based on convective inhibition (CIN), which are important for simple dynamical models such as Mapes (2000) and Raymond and Fuchs (2007)]. In our simulations, there are some robust changes in CCEW wave speed and variance, and even mean precipitation structure between the different convective parameterization frameworks of the ArakawaSchubert family and the Kuo scheme. Work is underway to compare these results with other GCMs, with the ultimate goals of improving convective parameterizations and building a better understanding of the effect of moisture on large-scale tropical dynamics. 
Acknowledgments. DMWF is supported by NSF Grant ATM-0846641 and a startup grant from the University of Washington. ISK is supported by the National Research Foundation of Korea Grant Funded by Korean Government (MEST) (NRF-2009-C1AAA001-2009-0093042) and the second phase of Brain Korea 21.

\section{REFERENCES}

Arakawa, A., and W. H. Schubert, 1974: Interaction of a cumulus cloud ensemble with the large-scale environment, Part I. J. Atmos. Sci., 31, 674-701.

Back, L. E., and C. S. Bretherton, 2006: Geographic variability in the export of moist static energy and vertical motion profiles in the tropical Pacific. Geophys. Res. Lett., 33, L17810, doi:10.1029/ 2006GL026672.

_- and —- 2009: On the relationship between SST gradients, boundary layer winds and convergence over the tropical oceans. J. Climate, 22, 4182-4196.

Betts, A. K., 1986: A new convective adjustment scheme. Part I: Observational and theoretical basis. Quart. J. Roy. Meteor. Soc., 112, 677-691.

_ and M. J. Miller, 1986: A new convective adjustment scheme. Part II: Single column tests using GATE wave, BOMEX ATEX, and arctic air-mass data sets. Quart. J. Roy. Meteor. Soc., 112, 693-709.

Bonan, G. B., 1996: A land surface model (LSM version 1.0) for ecological, hydrological, and atmospheric studies: Technical description and user's guide. NCAR Tech. Rep. NCAR/TN417, $150 \mathrm{pp}$.

Bony, S., and K. A. Emanuel, 2005: On the role of moist processes in tropical intraseasonal variability: Cloud-radiation and moisture-convection feedbacks. J. Atmos. Sci., 62, 2770-2789.

Bretherton, C. S., 2007: Challenges in numerical modeling of tropical circulations. The Global Circulation of the Atmosphere, T. Schneider and A. Sobel, Eds., Princeton University Press, 302-330. - P. N. Blossey, and M. E. Peters, 2006: Comparison of simple and cloud-resolving models of moist convection-radiation interaction with a mock-Walker circulation. Theor. Comput. Fluid Dyn., 20, 421-442, doi:10.1007/s00162-006-0029-7.

Dunkerton, T. J., and F. X. Crum, 1995: Eastward propagating 2- to 15-day equatorial convection and its relation to the tropical intraseasonal oscillation. J. Geophys. Res., 100, 25 781-25 790.

Flatau, M. K., P. J. Flatau, J. Schmidt, and G. N. Kiladis, 2003: Delayed onset of the 2002 Indian monsoon. Geophys. Res. Lett., 30, 1768, doi:10.1029/2003GL017434.

Frierson, D. M. W., 2007a: Convectively coupled Kelvin waves in an idealized moist general circulation model. J. Atmos. Sci., 64 2076-2090.

_ 2007b: The dynamics of idealized convection schemes and their effect on the zonally averaged tropical circulation. J. Atmos. Sci., 64, 1959-1976.

— - A. J. Majda, and O. M. Pauluis, 2004: Large scale dynamics of precipitation fronts in the tropical atmosphere: A novel relaxation limit. J. Comm. Math. Sci., 2, 591-626.

— I. M. Held, and P. Zurita-Gotor, 2006: A gray-radiation aquaplanet moist GCM. Part I: Static stability and eddy scale. J. Atmos. Sci., 63, 2548-2566.

Gill, A. E., 1980: Some simple solutions for heat induced tropical circulations. Quart. J. Roy. Meteor. Soc., 106, 447-462.

Haertel, P. T., and G. N. Kiladis, 2004: Dynamics of 2-day equatorial waves. J. Atmos. Sci., 61, 2707-2721.
Holtslag, A. A. M., and B. A. Boville, 1993: Local versus nonlocal boundary layer diffusion in a global climate model. J. Climate, 6, 1825-1842.

Itoh, H., 1989: The mechanism for the scale selection of tropical intraseasonal oscillations. Part I: Selection of wavenumber 1 and the three-scale structure. J. Atmos. Sci., 46, 1779-1798.

Kang, S. M., I. M. Held, D. M. W. Frierson, and M. Zhao, 2008: The response of the ITCZ to extratropical thermal forcing: Idealized slab-ocean experiments with a GCM. J. Climate, 21, 35213532.

, D. M. W. Frierson, and I. M. Held, 2009: The response of the ITCZ to extratropical forcing in a idealized GCM: The importance of radiative feedbacks and convective parameterization. J. Atmos. Sci., 66, 2812-2827, doi:10.1175/ 2009JAS2924.1.

Kemball-Cook, S. R., and B. C. Weare, 2001: The onset of convection in the Madden-Julian oscillation. J. Climate, 14, 780-793.

Khouider, B., and A. J. Majda, 2006a: A simple multicloud parameterization for convectively coupled tropical waves. Part I: Linear analysis. J. Atmos. Sci., 63, 1308-1323.

, and _ 2006b: Model multi-cloud parameterizations for convectively coupled waves: Detailed nonlinear wave evolution. Dyn. Atmos. Oceans, 42, 59-80.

- and — 2006c: Multicloud convective parametrizations with crude vertical structure. Theor. Comput. Fluid Dyn., 20, 351-375.

- and —, 2007: A simple multicloud parameterization for convectively coupled tropical waves. Part II: Nonlinear simulations. J. Atmos. Sci., 64, 381-400.

Kiladis, G. N., K. H. Straub, and P. T. Haertel, 2005: Zonal and vertical structure of the Madden-Julian oscillation. J. Atmos. Sci., 62, 2790-2809.

, M. C. Wheeler, P. T. Haertel, K. H. Straub, and P. E. Roundy, 2009: Convectively coupled equatorial waves. Rev. Geophys., 47, RG2003, doi:10.1029/2008RG000266.

Kuang, Z., 2008: A moisture-stratiform instability for convectively coupled waves. J. Atmos. Sci., 65, 834-854.

Kuo, Y. H., 1974: Further studies of the parameterization of the influence of cumulus convection of large-scale flow. J. Atmos. Sci., 31, 1232-1240.

Lee, M.-I., I.-S. Kang, and B. E. Mapes, 2003: Impacts of cumulus convection parameterization on aqua-planet AGCM simulations of tropical intraseasonal variability. J. Meteor. Soc. Japan, 81, 963-992.

Le Treut, H., and Z.-X. Li, 1991: Sensitivity of an atmospheric general circulation model to prescribed SST changes: Feedback effects associated with the simulation of cloud optical properties. Climate Dyn., 5, 175-187.

Liebmann, B., G. N. Kiladis, L. M. V. Carvalho, C. Jones, C. S. Vera, I. Bladé, and D. Allured, 2009: Origin of convectively coupled Kelvin waves over South America. J. Climate, 22, 300-315.

Lin, J.-L., 2007: The double-ITCZ problem in IPCC AR4 coupled GCMs: Ocean-atmosphere feedback analysis. J. Climate, 20, 4497-4525.

— , and Coauthors, 2006: Tropical intraseasonal variability in 14 IPCC AR4 climate models. Part I: Convective signals. J. Climate, 19, 2665-2690.

, D. Kim, M.-I. Lee, and I.-S. Kang, 2007: Effects of cloudradiative heating on atmospheric general circulation model (AGCM) simulations of convectively coupled equatorial waves. J. Geophys. Res., 112, D24107, doi:10.1029/2006JD008291. 
— M.-I. Lee, D. Kim, I.-S. Kang, and D. M. W. Frierson, 2008: The impacts of convective parameterization and moisture triggering on AGCM-simulated convectively coupled equatorial waves. J. Climate, 21, 883-909.

Lindzen, R. S., and S. Nigam, 1987: On the role of sea surface temperature gradients in forcing low-level winds and convergence in the tropics. J. Atmos. Sci., 44, 2418-2436.

Majda, A. J., and M. Shefter, 2001: Models for stratiform instability and convectively coupled waves. J. Atmos. Sci., 58, 1567-1584.

Maloney, E. D., and D. L. Hartmann, 1998: Frictional moisture convergence in a composite life cycle of the Madden-Julian oscillation. J. Climate, 11, 2387-2403.

Manabe, S., J. Smagorinsky, and R. F. Strickler, 1965: Simulated climatology of a general circulation model with a hydrologic cycle. Mon. Wea. Rev., 93, 769-798.

Mapes, B. E., 2000: Convective inhibition, subgrid-scale triggering energy, and stratiform instability in a toy tropical wave model. J. Atmos. Sci., 57, 1515-1535.

— S. Tulich, J. Lin, and P. Zuidema, 2006: The mesoscale convection life cycle: Building block or prototype for large-scale tropical waves? Dyn. Atmos. Oceans, 42, 3-29, doi:10.1016/ j.dynatmoce.2006.03.003.

Masunaga, H., 2007: Seasonality and regionality of the MaddenJulian oscillation, Kelvin wave, and equatorial Rossby wave. J. Atmos. Sci., 64, 4400-4416.

Matsuno, T., 1966: Quasi-geostrophic motions in the equatorial area. J. Meteor. Soc. Japan, 44, 25-43.

Mechoso, C. R., and Coauthors, 1995: The seasonal cycle over the tropical Pacific in coupled ocean-atmosphere general circulation models. Mon. Wea. Rev., 123, 2825-2838.

Moorthi, S., and M. J. Suarez, 1992: Relaxed Arakawa-Schubert: A parameterization of moist convection for general circulation models. Mon. Wea. Rev., 120, 978-1002.

Mounier, F., G. N. Kiladis, and S. Janicot, 2007: Analysis of the dominant mode of convectively coupled Kelvin waves in the West African monsoon. J. Climate, 20, 1487-1503.

Myers, D. S., and D. E. Waliser, 2003: Three-dimensional water vapor and cloud variations associated with the Madden-Julian oscillation during Northern Hemisphere winter. J. Climate, 16, 929-950.

Nakajima, T., M. Tsukamoto, Y. Tsushima, and A. Numaguti, 1995: Modelling of the radiative processes in an AGCM. Climate System Dynamics and Modelling, T. Matsuno, Ed., University of Tokyo Press, 104-123.

Neelin, J. D., and I. M. Held, 1987: Modeling tropical convergence based on the moist static energy budget. Mon. Wea. Rev., 115, $3-12$.

— vective adjustment and the Madden-Julian oscillation. Part I: Analytical theory. J. Atmos. Sci., 51, 1876-1894.

— I. M. Held, and K. H. Cook, 1987: Evaporation-wind feedback and low-frequency variability in the tropical atmosphere. J. Atmos. Sci., 44, 2341-2348.

Nguyen, H., and J. P. Duvel, 2008: Synoptic wave perturbations and convective systems over equatorial Africa. J. Climate, 21, 6372-6388.

Numaguti, A., M. Takahashi, T. Nakajima, and A. Sumi, 1995: Development of an atmospheric general circulation model. Climate System Dynamics and Modelling, T. Matsuno, Ed., University of Tokyo Press, 1-27.

Peters, M. E., and C. S. Bretherton, 2005: A simplified model of the Walker circulation with an interactive ocean mixed layer and cloud-radiative feedbacks. J. Climate, 18, 4216-4234.
Raymond, D. J., 2001: A new model of the Madden-Julian oscillation. J. Atmos. Sci., 58, 2807-2819.

—, and Z. Fuchs, 2007: Convectively coupled gravity and moisture modes in a simple atmospheric model. Tellus, 59A, 627-640.

Raymond, D. L., S. L. Sessions, A. H. Sobel, and Z. Fuchs, 2009: The mechanics of gross moist stability. J. Adv. Model. Earth Syst., 1, 9, doi:10.3894/JAMES.2009.1.9.

Roundy, P. E., 2008: Analysis of convectively coupled Kelvin waves in the Indian Ocean MJO. J. Atmos. Sci., 65, 1342-1359. , and W. M. Frank, 2004: A climatology of waves in the equatorial region. J. Atmos. Sci., 61, 2105-2132.

Satoh, M., 1994: Hadley circulations in radiative-convective equilibrium in an axially symmetric atmosphere. J. Atmos. Sci., $\mathbf{5 1}$, 1947-1968.

Seo, K.-H., and K.-Y. Kim, 2003: Propagation and initiation mechanisms of the Madden-Julian oscillation. J. Geophys. Res., 108, 4384, doi:10.1029/2002JD002876.

Slingo, J. M., and Coauthors, 1996: Intraseasonal oscillations in 15 atmospheric general circulation models: Results from an AMIP diagnostic subproject. Climate Dyn., 12, 325-357.

Sobel, A. H., and C. S. Bretherton, 2003: Large-scale waves interacting with deep convection in idealized mesoscale model simulations. Tellus, 55A, 45-60.

_ , and J. D. Neelin, 2006: The boundary layer contribution to intertropical convergence zones in the quasi-equilibrium tropical circulation model framework. Theor. Comput. Fluid Dyn., 20, 323-350.

_ - J. Nilsson, and L. M. Polvani, 2001: The weak temperature gradient approximation and balanced tropical moisture waves. J. Atmos. Sci., 58, 3650-3665.

- C. S. Bretherton, H. Gildor, and M. Peters, 2004: Convection, cloud-radiative feedbacks, and thermodynamic ocean coupling in simple models of the Walker circulation. A Global Survey of Ocean-Atmosphere Interaction and Climate Variability, Geophys. Mongr., Vol. 147, Amer. Geophys. Union, 393-405.

Sperber, K. R., 2003: Propagation and the vertical structure of the Madden-Julian oscillation. Mon. Wea. Rev., 131, 3018-3037.

Straub, K. H., and G. N. Kiladis, 2002: Observations of a convectively coupled Kelvin wave in the eastern Pacific ITCZ. J. Atmos. Sci., 59, 30-53.

$\longrightarrow$, and - 2003a: Extratropical forcing of convectively coupled Kelvin waves during austral winter. J. Atmos. Sci., 60, 526-543.

, and - 2003b: The observed structure of convectively coupled Kelvin waves: Comparison with simple models of coupled wave instability. J. Atmos. Sci., 60, 1655-1668.

,-- , and P. E. Ciesielski, 2006: The role of equatorial waves in the onset of the South China Sea summer monsoon and the demise of El Niño during 1998. Dyn. Atmos. Oceans, 42, 216-238.

_ - P. T. Haertel, and G. N. Kiladis, 2010: An analysis of convectively coupled Kelvin waves in 20 WCRP CMIP3 global coupled climate models. J. Climate, 23, 3031-3056.

Tian, B., and V. Ramanathan, 2003: A simple moist tropical atmosphere model: The role of cloud radiative forcing. J. Climate, 16, 2086-2092.

_, D. E. Waliser, E. J. Fetzer, B. H. Lambrigtsen, Y. Yung, and B. Wang, 2006: Vertical moist thermodynamic structure and spatial-temporal evolution of the MJO in AIRS observations. J. Atmos. Sci., 63, 2462-2485.

Tiedtke, M., 1983: The sensitivity of the time-mean large-scale flow to cumulus convection in the ECMWF model. Proc. Workshop 
on Convection in Large-Scale Numerical Models, Reading, United Kingdom, ECMWF, 297-316.

Tokioka, T., K. Yamazaki, A. Kitoh, and T. Ose, 1988: The equatorial 30-60-day oscillation and the Arakawa-Schubert penetrative cumulus parameterization. J. Meteor. Soc. Japan, 66, 883-901.

Tulich, S. N., and B. E. Mapes, 2008: Multiscale convective wave disturbances in the tropics: Insights from a two-dimensional cloud-resolving model. J. Atmos. Sci., 65, 140-155.

- D. A. Randall, and B. E. Mapes, 2007: Vertical-mode and cloud decomposition of large-scale convectively coupled gravity waves in a two-dimensional cloud-resolving model. J. Atmos. Sci., 64, 1210-1229.

—, G. N. Kiladis, and A. Suzuki-Parker, 2010: Convectively coupled Kelvin and easterly waves in a regional climate simulation of the tropics. Climate Dyn., in press, doi:10.1007/ s00382-009-0697-2.

Uppala, S., D. Dee, S. Kobayashi, P. Berrisford, and A. Simmons, 2008: Towards a climate data assimilation system: Status update of ERA-Interim. ECMWF Newsletter, No. 115, ECMWF, Reading, United Kingdom, 12-18. [Available online at http:// www.ecmwf.int/publications/newsletters/pdf/115.pdf.]

Wang, H., and R. Fu, 2007: The influence of Amazon rainfall on the Atlantic ITCZ through convectively coupled Kelvin waves. J. Climate, 20, 1188-1201.
Wang, W., and M. E. Schlesinger, 1999: The dependence of convective parameterization of the tropical intraseasonal oscillation simulated by the UIUC 11-layer atmospheric GCM. J. Climate, 12, 1423-1457.

Wheeler, M., and G. N. Kiladis, 1999: Convectively coupled equatorial waves: Analysis of clouds and temperature in the wavenumber-frequency domain. J. Atmos. Sci., 56, 374-399.

- — - and P. J. Webster, 2000: Large-scale dynamical fields associated with convectively coupled equatorial waves. $J$. Atmos. Sci., 57, 613-640.

Yang, G.-Y., B. Hoskins, and J. Slingo, 2007a: Convectively coupled equatorial waves. Part I: Horizontal and vertical structures. J. Atmos. Sci., 64, 3406-3423.

and $-2007 \mathrm{~b}$ : Convectively coupled equatorial waves. Part II: Propagation characteristics. J. Atmos. Sci., 64, 3424-3437. - - , and,$- 2007 \mathrm{c}$ : Convectively coupled equatorial waves. Part III: Synthesis structures and their forcing and evolution. J. Atmos. Sci., 64, 3438-3451.

Yu, J.-Y., C. Chou, and J. D. Neelin, 1998: Estimating the gross moist stability of the tropical atmosphere. J. Atmos. Sci., 55, 1354-1372.

Zhang, G. J., and M. Mu, 2005: Simulation of the Madden-Julian Oscillation in the NCAR CCM3 using a revised ZhangMcFarlane convection parameterization scheme. J. Climate, 18, 4046-4064. 